\title{
Avulsion injuries: an update on radiologic findings
}

\author{
Changwon Choi ${ }^{1}$, Sun Joo Lee ${ }^{1}$, Hye Jung Choo ${ }^{1}$, In Sook Lee ${ }^{2,3}$, Sung Kwan Kim ${ }^{4}$ \\ ${ }^{1}$ Department of Radiology, Inje University Busan Paik Hospital, Inje University College of Medicine, Busan, Korea \\ ${ }^{2}$ Department of Radiology, Pusan National University Hospital, Busan, Korea \\ ${ }^{3}$ Biomedical Research Institute, Pusan National University School of Medicine, Busan, Korea \\ ${ }^{4}$ Department of Radiology, Busan Himchan Hospital, Busan, Korea
}

Received: May 7, 2021

Revised: June 8, 2021

Accepted: June 22, 2021

Corresponding author:

Sun Joo Lee, MD

Department of Radiology, Inje

University Busan Paik Hospital, Inje

University College of Medicine, 75

Bokji-ro, Busanjin-gu, Busan 47392,

Korea

Tel: +82-51-890-6579

Fax: +82-51-896-1085

E-mail: sunjulee98@naver.com
Avulsion injuries result from the application of a tensile force to a musculoskeletal unit or ligament. Although injuries tend to occur more commonly in skeletally immature populations due to the weakness of their apophysis, adults may also be subject to avulsion fractures, particularly those with osteoporotic bones. The most common sites of avulsion injuries in adolescents and children are apophyses of the pelvis and knee. In adults, avulsion injuries commonly occur within the tendon due to underlying degeneration or tendinosis. However, any location can be involved in avulsion injuries. Radiography is the first imaging modality to diagnose avulsion injury, although advanced imaging modalities are occasionally required to identify subtle lesions or to fully delineate the extent of the injury. Ultrasonography has a high spatial resolution with a dynamic assessment potential and allows the comparison of a bone avulsion with the opposite side. Computed tomography is more sensitive for depicting a tiny osseous fragment located adjacent to the expected attachment site of a ligament, tendon, or capsule. Moreover, magnetic resonance imaging is the best imaging modality for the evaluation of soft tissue abnormalities, especially the affected muscles, tendons, and ligaments. Acute avulsion injuries usually manifest as avulsed bone fragments. In contrast, chronic injuries can easily mimic other disease processes, such as infections or neoplasms. Therefore, recognizing the vulnerable sites and characteristic imaging features of avulsion fractures would be helpful in ensuring accurate diagnosis and appropriate patient management. To this end, familiarity with musculoskeletal anatomy and mechanism of injury is necessary.

Keywords: Apophyseal injury; Avulsion fractures; Diagnosis; Cumulative trauma disorders; Athletic injuries; Therapeutics

\section{Introduction}

In modern society, sports activities play an important role in the lives of many people. With an increasing number of people participating in dynamic sports activities, avulsion injuries are becoming more prevalent. Skeletally immature athletes are at particular risk for injuries at the apophysis, as it is weaker than the attached muscle-tendon unit. Certain types of avulsion fractures are seen more frequently in elderly or osteoporotic patients [1,2]. There are two distinct types of avulsion injuries: acute and chronic. Acute avulsion injuries result from sudden, forceful, or unbalanced contraction of the musculotendinous unit [1]. In contrast, chronic injuries are due to repetitive submaximal force, which may result in minimal displacement or widening of the physis [1]. In acute injuries, athletes experience sudden, shooting pain, swelling, and local tenderness. A clear history is available in most cases

Copyright (C) 2021 Yeungnam University College of Medicine

This is an Open Access article distributed under the terms of the Creative Commons Attribution Non-Commercial License (http://creativecommons.org/licenses/by-nc/4.0/) which permits unrestricted non-commercial use, distribution, and reproduction in any medium, provided the original work is properly cited. 
of apophyseal injuries. The diagnosis is easily confirmed on the basis of physical findings, symptoms, patient's age, biomechanical analysis of the injury, and radiography. However, patients with chronic overuse injuries usually present with a gradual onset of pain and have no clear history of trauma. Radiographs may also show normal findings, which confounds the diagnosis. In addition, posttraumatic bone changes may resemble other disease conditions, such as inflammation or neoplasm $[3,4]$. Therefore, imaging plays an important role in detecting and understanding avulsion fractures. Computed tomography $(\mathrm{CT})$ is helpful for detecting tiny avulsed bone fragments in cases showing inadequate or equivocal radiographic findings [4]. Ultrasonography (US) with a high-frequency transducer has the advantages of no exposure to radiation, early detection even without an ossification center, and the possibility of dynamic examination [5]. However, the usefulness of US is limited in cases showing artifacts or lesions in a deep location. Magnetic resonance imaging (MRI) is the best modality for evaluating edematous changes in bone and soft tissue that help radiologists detect the affected muscles, tendons, ligaments, and associated bony lesions [3,4].

To avoid performing excessive imaging and biopsies or making incorrect diagnoses, anatomical knowledge and understanding of the pathophysiology of avulsion injuries are important. In this review, we summarize and illustrate the musculoskeletal anatomy and the radiographic, US, CT, and MRI features of avulsion injuries in the whole body, including the lower extremity (e.g., pelvis and femur, knee, ankle, and foot) and upper extremity (e.g., shoulder, elbow, and hand) (Fig. 1).

\section{Pelvis and femur avulsion injuries}

Acute avulsion injuries of the pelvis and femur are divided into two groups based on the mechanism underlying the injury. The most common injury mechanism is an abrupt, strong concentric or eccentric contraction of a large muscle that occurs during an attempt to accelerate or decelerate the body mass [6-8]. The second mechanism is abrupt immoderate passive lengthening, which can cause ischial avulsion in dancers or cheerleaders and can occur in individuals performing anteroposterior stretching or "the splits" without external force $[6,8]$. Apophyseal avulsion injuries of the hip and pelvis usually occur in adolescent athletes and can occur in athletes as late as their mid-20s [6]. The apophyseal physis usually fuses later than the physes of long bones [8].

In the largest study evaluating these injuries, Rossi and Dragoni [9] found that the most common locations were the ischial tuberosity (54\%), the anterior inferior iliac spine (AIIS) (22\%), the anterior superior iliac spine (ASIS) (19\%), the superior corner of the pubic symphysis (3\%), and the iliac crest (1\%). Common avulsion injuries of the femur occur at the greater and lesser trochanters (Fig. 1).

\section{Ischial tuberosity avulsion fracture}

The ischial tuberosity is the insertion site of the adductor muscle and hamstring muscle group, which is composed of the semimembranosus, biceps femoris, and semitendinosus. A forceful pull on these muscles before the apophysis is closed leads to the avulsion of the open ischial apophysis [8]. An avulsion injury is caused by extreme contraction of the hamstring muscles during high-speed running, for example, during sprinting, or when stretching is performed at an extreme joint position, for example, during water skiing or playing American football [10]. Patients present with extensive buttock pain, ecchymosis, swelling, bruising in the thigh, and decreased hamstring strength. In the acute phase, ischial epiphysiolysis presents as a non-displaced avulsion on a radiograph, which appears as a curved, well-demarcated bone fragment adjacent to its origin [1]. US, CT, and MRI can be useful for diagnosis if radiographs are normal or subtle. MRI is the most accurate imaging tool for diagnosis, especially for identifying non-displaced or minimally displaced avulsion $[1,3]$. On MRI, acute avulsion injuries appear as focal fluid signal intensity intervening between the tendon edge and the ischial tuberosity (Fig. 2). Fluid collection and soft tissue edema are often observed at the site of injury $[3,11]$. Chronic avulsion injuries often result in prominent heterotopic bone formation or callus formation, which mimics osteomyelitis or Ewing sarcoma [1,8]. In such cases, CT may be helpful for the diagnosis [12]. Acute avulsion injuries with a displacement of $<15 \mathrm{~mm}$ tend to respond well to conservative treatment. Early surgical intervention can be considered for injuries with significant displacement $(>15 \mathrm{~mm})[13,14]$.

\section{Anterior superior iliac spine and anterior inferior iliac spine avulsion fractures}

Other commonly involved avulsion sites in the pelvis are the ASIS and the AIIS. The ASIS is the attachment site of the sartorius and tensor fascia lata, while the AIIS is the origin of the straight head of the rectus femoris. Avulsion injuries of the ASIS and AIIS are commonly believed to result from forceful extension of the hip and flexion of the knee during sports activities, especially during the kicking phase of soccer or rugby and the starting phase of running or jumping $[15,16]$. Direct trauma or chronic traction rarely causes avulsion injuries. Most patients report acute pain in the iliac region and sometimes show a palpable bony fragment in these regions. Radiographs usually show avulsion fractures of the apophysis involved. However, radiographic findings for non-ossi- 


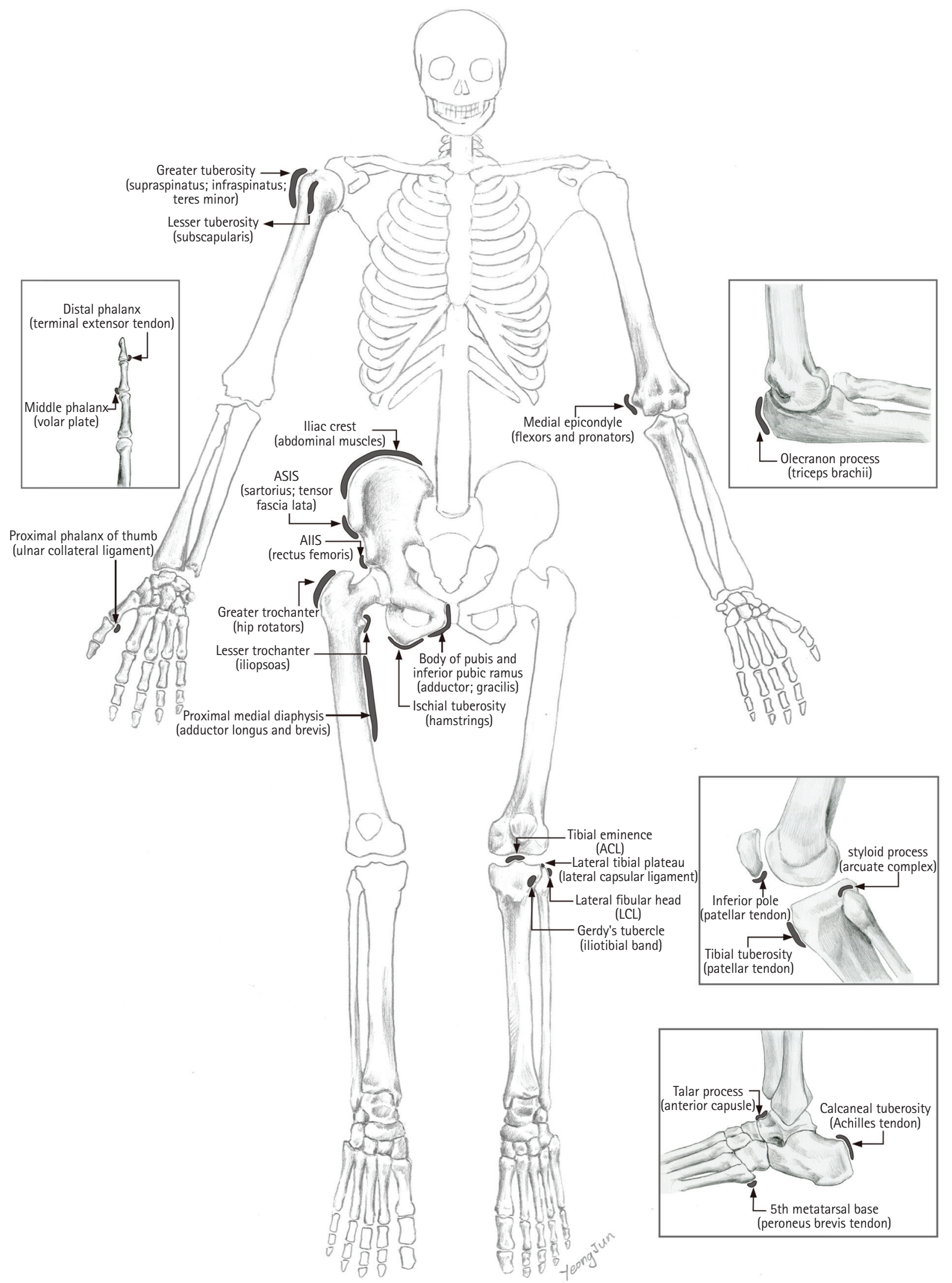

Fig. 1. The diagram shows the vulnerable sites for avulsion injuries in the body. ASIS, anterior superior iliac spine; AllS, anterior inferior iliac spine; ACL, anterior cruciate ligament; LCL, lateral collateral ligament. Provided by Inje University Busan Paik Hospital. 

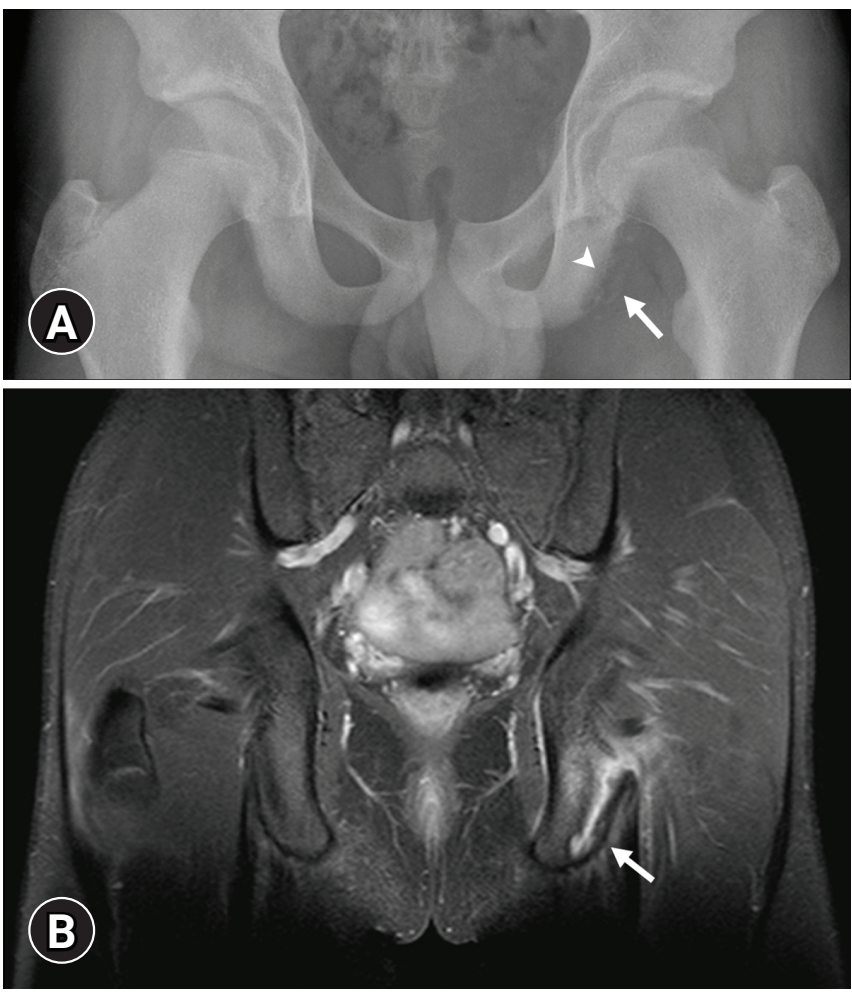

Fig. 2. Avulsion of the ischial tuberosity in a 16-year-old soccer player with pain for 1 month in the left gluteal region. (A) The anteroposterior radiograph of the pelvis reveals small bone fragments (arrow) around the left ischial tuberosity, which has a cortical irregularity (arrowhead). (B) The coronal T2-weighted magnetic resonance image with fat saturation shows bone marrow edema at the widened apophysis of the left ischial tuberosity (arrow). Provided by Inje University Busan Paik Hospital.

fied apophysis can be occult and confusing due to skeletal immaturity. In this case, CT and US can depict a small bone fragment, and MRI can show edema of the affected bone and muscles and fluid collection around the avulsed site (Figs. 3, 4) [17]. The treatment of avulsion injuries of the iliac spine is usually conservative and has a relatively shorter recovery time compared to injuries of the ischial tuberosity. However, surgical treatment has been advocated for patients with the displacement of the avulsed fragment $>2 \mathrm{~cm}$, continued pain following nonunion, or impingement syndrome $[14,18]$.

\section{Iliac crest avulsion fracture}

Avulsion injury of the iliac crest is uncommon and results from the sudden contraction of the abdominal muscles, including the external and internal abdominal oblique, transverse abdominis, gluteus medius, and tensor fascia latae muscles [15]. The iliac crest apophysis remains cartilaginous until adolescence; the fusion of the ossified apophysis to the iliac bone begins at approxi-
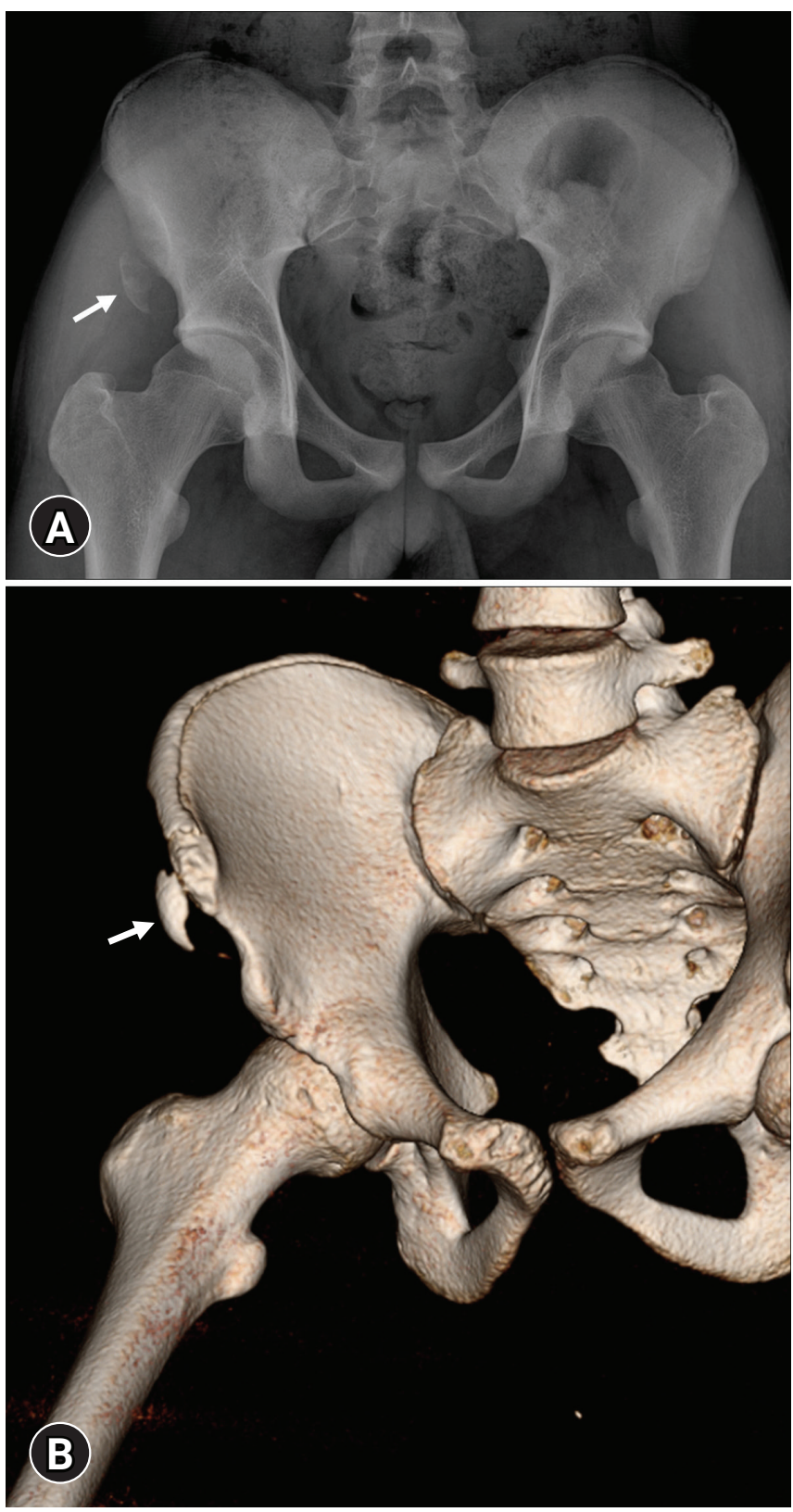

Fig. 3. Avulsion of the anterior superior iliac spine (ASIS) in a 17-year-old soccer player with pain for 2 weeks in the right hip. (A) The anteroposterior radiograph and (B) the three-dimensional volume-rendered image of the pelvis show an avulsion fracture of the ASIS (arrows). The bone fragment is sharply defined and displaced inferiorly. Provided by Inje University Busan Paik Hospital.

mately 15 years of age [19], increasing the vulnerability to overuse and acute and chronic trauma. Clinical examination reveals pain, point tenderness, and swelling along the iliac crest. Asymmetry and apophyseal widening $(>2 \mathrm{~mm}$ ) of the iliac crest is a radiographic indication of avulsion injury [19]. Segmentation of the apophysis, which is a developmental variant, should not be mistaken for an avulsion of the apophysis. Comparison with the con- 

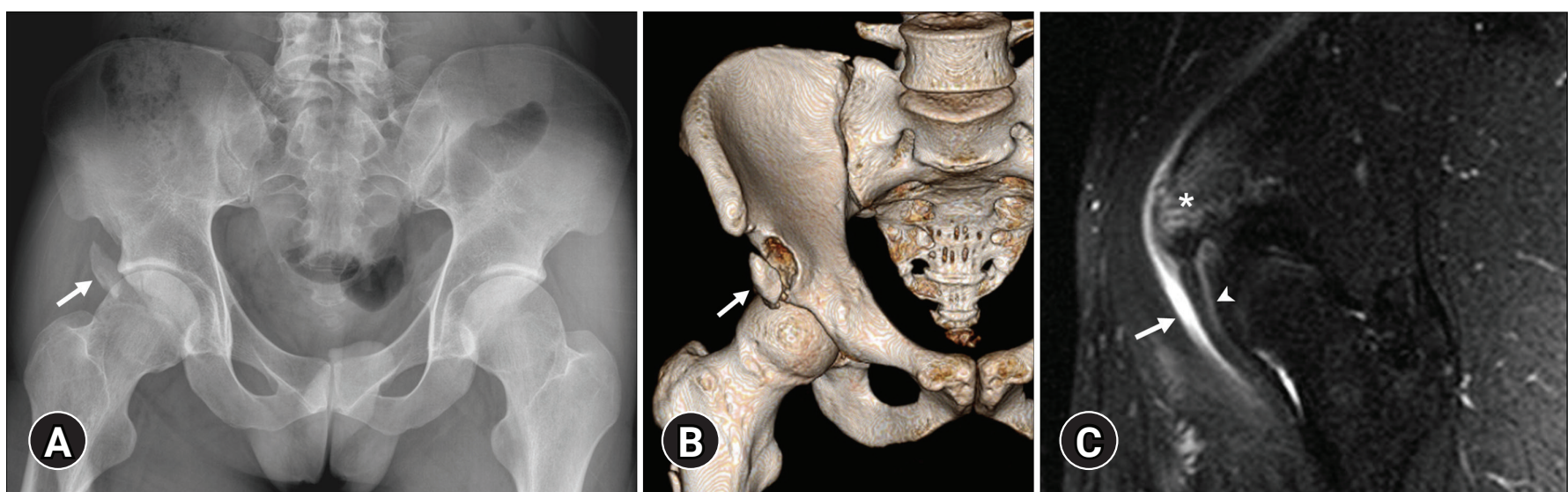

Fig. 4. Avulsion of the anterior inferior iliac spine (AIIS) in a 27-year-old sprinter with pain for 2 days in the right hip. (A) The anteroposterior radiograph of the pelvis and (B) the three-dimensional volume-rendered image show an avulsion fracture of the AllS (arrows). The bone fragment is sharply defined and displaced inferiorly. (C) The sagittal T2-weighted magnetic resonance image with fat saturation reveals a high signal intensity (arrow) around the proximal rectus femoris tendon (arrowhead) and bone marrow edema of the AlIS (asterisk). Provided by Inje University Busan Paik Hospital.
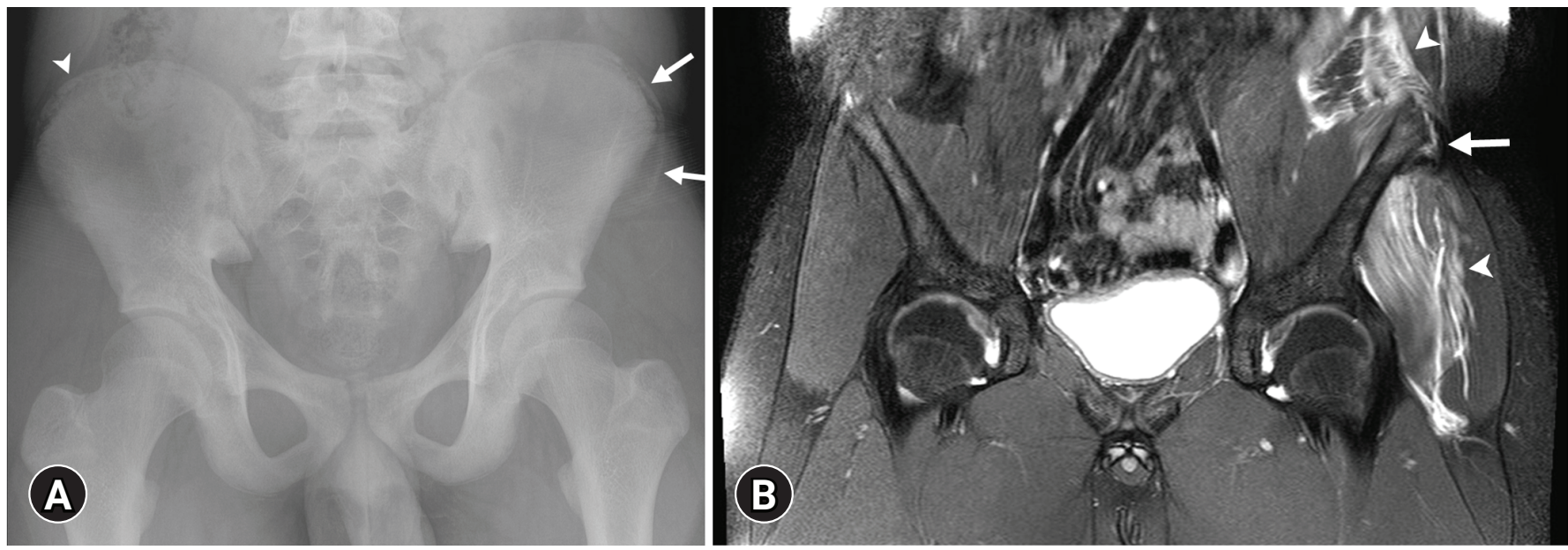

Fig. 5. Avulsion of the iliac crest in a 15-year-old soccer player with pain in the left buttock for 1 year. (A) The anteroposterior radiograph of the pelvis reveals mild widening of the left iliac apophysis (arrows). Normal fragmentation is seen on the right iliac crest (arrowhead). (B) The coronal T2-weighted magnetic resonance image with fat saturation shows an avulsed apophysis (arrow) and edema at the left abdominis muscles, psoas, and gluteus minimus muscles (arrowheads). Provided by Inje University Busan Paik Hospital.

tralateral side might be helpful in differentiating the segmentation of the apophysis from avulsion. However, iliac crest avulsion is sometimes bilateral, which may cause problems in making an accurate diagnosis. In such cases, MRI may be helpful. MRI demonstrates displacement of the apophysis with fluid-like signal intensity in the disrupted physis of the iliac crest and adjacent soft tissue edema (Fig. 5) [3]. Relatively good clinical outcomes are achieved by conservative treatment alone. Surgical treatment can be performed in cases with a fragment displacement of $>3 \mathrm{~cm}$ or persistent symptoms $[15,20]$.

\section{Pubic symphysis avulsion fracture}

The symphysis pubis and inferior pubic ramus are the origins of the adductor longus, adductor brevis, and gracilis muscles. Injuries in this region are secondary to chronic repetitive microtrauma with excessive twisting and turning movements of the body and commonly occur in those involved in soccer, ice hockey, fencing, and tennis [1,3]. However, it may also occur acutely, such as when two soccer players kick the ball simultaneously [1]. The most sensitive imaging modality for these lesions is MRI because these injuries do not often result in a displaced fragment but rather present as a soft tissue injury $[3,15]$. There are no specific treatment guidelines for pubic symphysis avulsions. However, conservative 
treatment may be a safe option and may be superior to surgical treatment $[21,22]$.

\section{Femur avulsion fracture}

Avulsion injuries of the greater or lesser trochanter are less common than pelvic avulsion injuries; however, these lesions cause substantial pain and dysfunction. The greater and lesser trochanters are the insertion sites for the hip rotators and iliopsoas muscles, respectively. Avulsion injuries of the greater trochanter may occur following forced external rotation of the leg with contraction of the gluteus medius and gluteus minimus muscles. Fractures of the greater trochanter can lead to osteonecrosis of the femoral head $[1,23]$. In adults, isolated fractures of the lesser trochanter without a history of trauma are usually secondary to metastatic disease. However, avulsion injuries in children and adolescents may occur in sprinters or jumpers during forceful contraction of the iliopsoas tendon with hip flexion $[24,25]$. On plain radiography, avulsed bone fragments are seen displaced from their origin in many patients (Fig. 6). A confusing radiograph of patients with an uncertain clinical history sometimes requires an additional MRI to evaluate the muscles, ligaments, and underlying lesions of the femur (e.g., metastatic nodules). Conservative treatment of the lesser trochanter avulsion shows excellent results in most cases [25]. However, there is no consensus on the best treatment for avulsion injury of the greater trochanter [26].

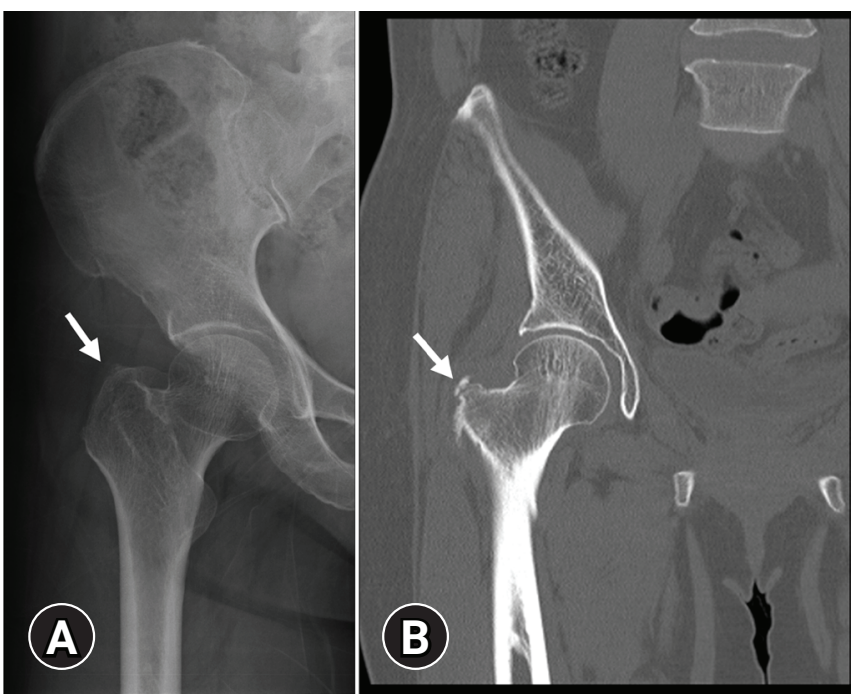

Fig. 6. Avulsion of the greater trochanter in a 53-year-old woman with pain in the right hip for 1 day after a car accident. (A) The anteroposterior radiograph of the right hip faintly shows a small bone fragment (arrow) around the greater trochanter. (B) The coronal computed tomography image shows an avulsion fracture of the right greater trochanter (arrow) of the femur. The small bone fragment without displacement is well defined. Provided by Inje University Busan Paik Hospital.

\section{Thigh splints}

Adductor insertion avulsion syndrome or thigh splints are stress-related avulsion injuries that occur at the insertion of the adductor muscles of the proximal medial diaphysis of the femur. Radiographs may be normal in the early stage but may later show a periosteal reaction along the posteromedial cortex of the femoral shaft and possible stress fracture $[27,28]$. MRI of these lesions presents with periosteal edema and abnormal signal intensity in the medullary cavity or cortex (Fig. 7). These findings can easily be misinterpreted as osteomyelitis or malignant neoplasms, such as Ewing's sarcoma or osteosarcoma. The absence of bone destruction and soft tissue mass helps to rule out these conditions $[28,29]$. In addition, the clinical history, location, and symptoms are important in differentiating avulsion injuries from other pathologic conditions. These injuries usually respond relatively quickly to rest for 1-2 months [28].

\section{Knee avulsion injuries}

The knee joint is another common site of avulsion injury. The knee joint is a complex joint composed of numerous tendinous, ligamentous, and meniscal attachments that are vulnerable to trauma. A variety of avulsion fractures of the knee can occur, including Segond and reverse Segond fractures, avulsions of the anterior and posterior cruciate ligaments, arcuate complex avulsion, iliotibial band avulsion, avulsions of the biceps femoris, semimembranosus, and quadriceps tendons, Sinding-Larsen-Johansson syndrome, and Osgood-Schlatter disease [30]. Complex knee injuries result from multiple forces such as varus force, valgus force, hyperextension, hyperflexion, internal rotation, external rotation, anterior or posterior translation, and axial load [31].

\section{Segond fracture}

Segond fracture was classically described as a cortical avulsion of the lateral capsular ligament at the anterolateral proximal tibia. This injury occurs following excessive tension to the lateral capsular ligament due to varus stress on the partially flexed and internally rotated knee $[32,33]$. Previous descriptions of this ligament include different nomenclatures such as the lateral capsular ligament $[32,33]$, the anterior oblique band of the fibular collateral ligament [34], and the capsule-osseous layer of the iliotibial tract [35]. Recent studies described this structure as a distinct ligament, called "anterolateral ligament" [36,37], but there is no consensus in the terminology of the anterolateral capsular structure. This injury is commonly associated with anterior cruciate ligament (ACL) tears in the adult population [34,38]. However, in skeletally immature patients, the association between Segond 

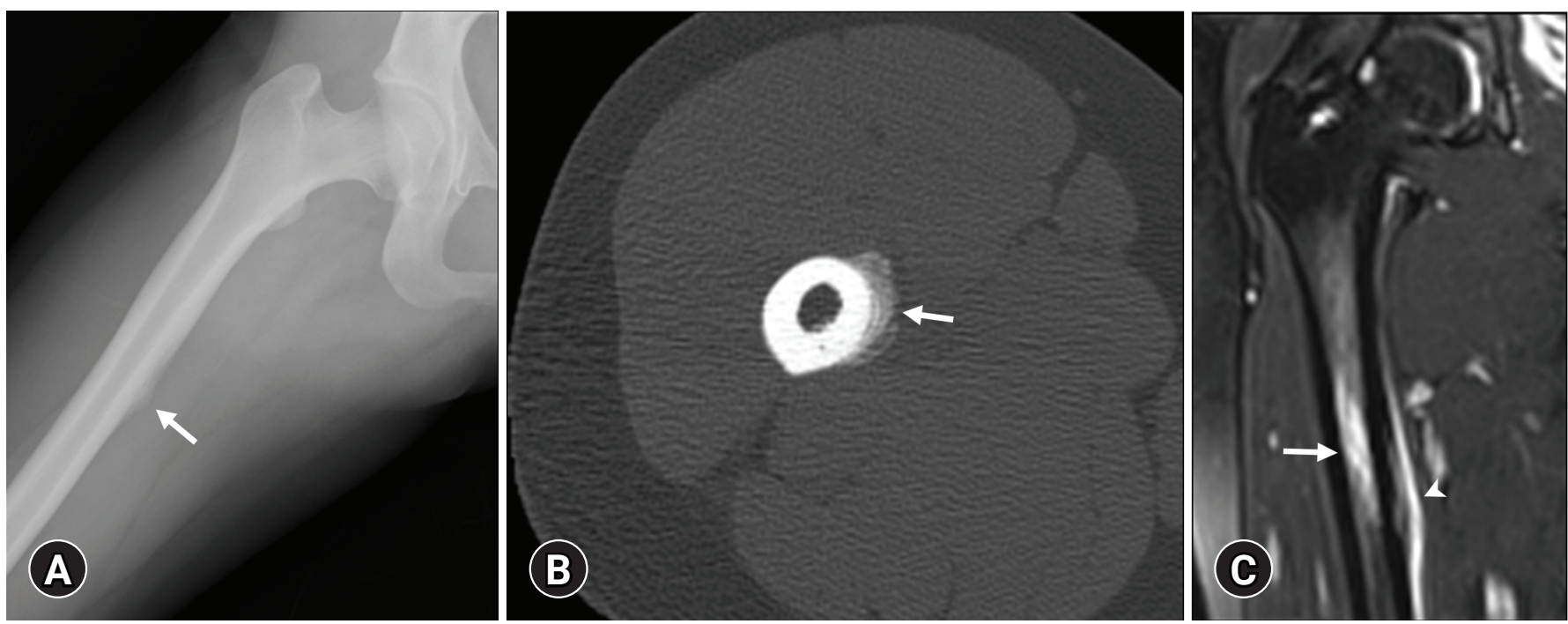

Fig. 7. Adductor insertion avulsion syndrome in a 19-year-old ballet dancer with pain in the right thigh for 3 weeks. (A) The anteroposterior radiograph and (B) the axial computed tomography image of the femur show periosteal reaction (arrow) at the proximal medial diaphysis of the femur. (C) The coronal T2-weighted magnetic resonance image with fat saturation shows bone marrow edema (arrow) and periosteal reaction (arrowhead) at the medial diaphysis of the proximal femur, which is the attachment site for the adductor longus. Provided by Inje University Busan Paik Hospital.

fracture and ACL tear may not be definitive [39]. The mechanism of this injury results from varus stress on the partially flexed and internally rotated knee [30]. These injuries are important because they may be the only radiologic clue to more serious underlying ligamentous injuries, which vary from an ACL tear to avulsion of the fibular collateral ligament or tibiofibular joint sprains $[37,38]$. The clinical manifestation of this injury is pain at the lateral joint line with anterolateral instability. The radiograph shows an elliptic bone fragment parallel to the tibia, just below the lateral tibial plateau. In equivocal radiographs, CT more easily shows bone fragments. MRI is generally not required but should be performed to evaluate the associated ligaments and meniscal tears (Fig. 8) $[38,40]$. The treatment of this injury is based on the severity of the associated ACL and meniscal injuries.

\section{Anterior cruciate ligament avulsion fracture}

Tibial eminence is the insertion site of the ACL. Although most ACL injuries involve the mid-substance of the ligament, avulsion injury at the tibial insertion site of the ACL rarely occurs and is more common in children than in adults [41]. The clinical manifestations of this injury are pain, flexed knee, and signs of anterior instability [42]. In the pediatric population, this injury commonly occurs with forced flexion of the knee and internal rotation of the tibia. On the other hand, in the adult population, this injury results from forced knee extensions that commonly occur in motor vehicle collisions. This injury in the adult population is more frequently associated with medial collateral liga-
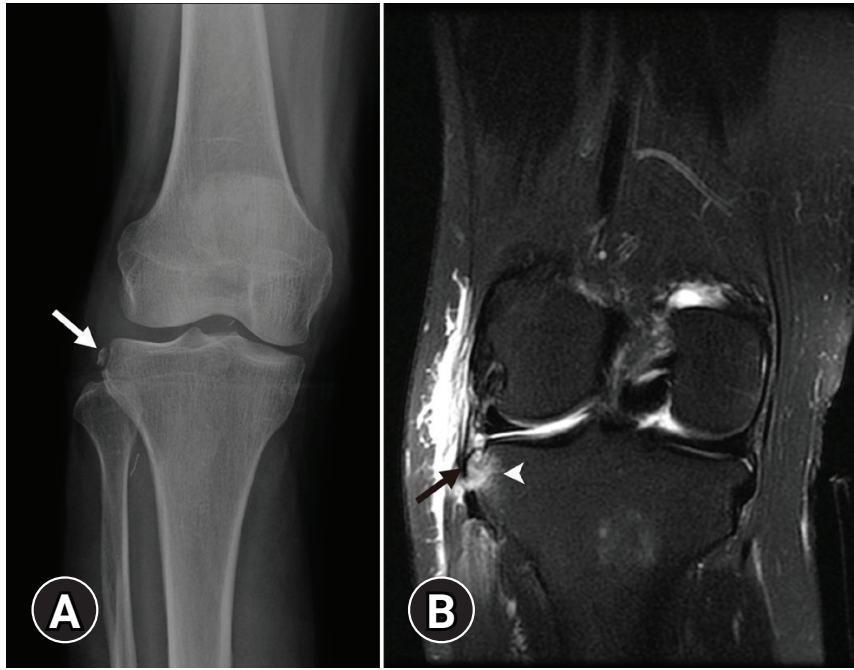

Fig. 8. A Segond fracture in a 67-year-old woman who sustained a rotational injury to the knee. (A) The anteroposterior radiograph of the knee shows an elliptic bone fragment (arrow) arising from the lateral tibial plateau. (B) The coronal T2-weighted magnetic resonance image with fat saturation shows a tiny bone fragment (arrow), which represents an avulsion of the lateral capsular ligament. Marrow edema along the lateral tibial rim (arrowhead) is also present. Provided by Inje University Busan Paik Hospital.

ment (MCL) injury, posterior cruciate ligament injury, and attached bone contusion [43]. On plain radiographs, an avulsed bone fragment can be detected. However, sometimes the bony fragment is small, which makes visualization difficult. In these circumstances, CT and MRI can be helpful for detecting bony 
fragments. Moreover, MRI is useful for assessing associated injuries and ACL status (Fig. 9). Injuries with minimally displaced bone fragments are treated conservatively, whereas injuries with markedly displaced bone fragments require surgical treatment (i.e., internal fixation) [44].

\section{Arcuate complex avulsion fracture}

The arcuate complex and posterolateral aspects of the knee have recently gained attention owing to their complex anatomy and clinical relevance. The arcuate complex primarily consists of the fabellofibular ligament, popliteofibular ligament (i.e., the fibular origin of the popliteus muscle), and the arcuate ligament [33]. The mechanisms of this injury involve forceful direct trauma to the anteromedial tibia with knee extension and varus force to the externally rotated tibia [45]. Clinical manifestations (e.g., swelling and posterior subluxation of the tibia) of this injury are subtle. This makes determining a diagnosis difficult. On plain radiographs, the avulsed bone fragment has a characteristic elliptical appearance arising from the fibular styloid process (i.e., the attachment site for the arcuate complex) and horizontal orientation of its long axis on the anteroposterior radiograph of the knee. This is called the "arcuate sign". The avulsion may not be conspicuous on a lateral radiograph because of its superimposition on the cortex of the posterior tibial plateau [46]. On MRI, the origin of the bone fragment and associated edema at the fibular head and contiguous soft tissue can be helpful signs for diagnosing this injury

\section{(Fig. 10) [46,47].}

Arcuate complex injuries are commonly associated with damage to other stabilizing structures of the knee and peroneal nerve. Other conditions encountered in the differential diagnosis of these injuries include injury of the lateral collateral ligament and tendon of the long head of the biceps femoris muscles that are attached to the lateral margin of the fibular head $[30,45]$. In patients with acute injuries, the primary repair is usually performed by repairing all injured structures [33].

\section{Iliotibial band avulsion fracture}

The iliotibial band is a complex composed of the tendon of the tensor fascia lata and the deep and superficial fibers of the fascia lata that provide anterolateral stabilization of the knee. The superficial layer is the chief tendinous component that inserts into the Gerdy's tubercle on the anterior lateral tibia, and the deep layer inserts into the intermuscular septum of the distal femur [33]. This injury only results from a varus force, which is a rare injury mechanism. Isolated tears of the iliotibial band are uncommon [31]. Avulsion fractures of the iliotibial band are usually associated with ACL injuries and patellar dislocations. MRI of this injury shows avulsion with retraction of the iliotibial band from its tibial donor site, the Gerdy's tubercle, and waviness of the torn fibers (Fig. 11) [48]. A wider injury pattern in patients frequently requires repair of the ruptured iliotibial band [33].
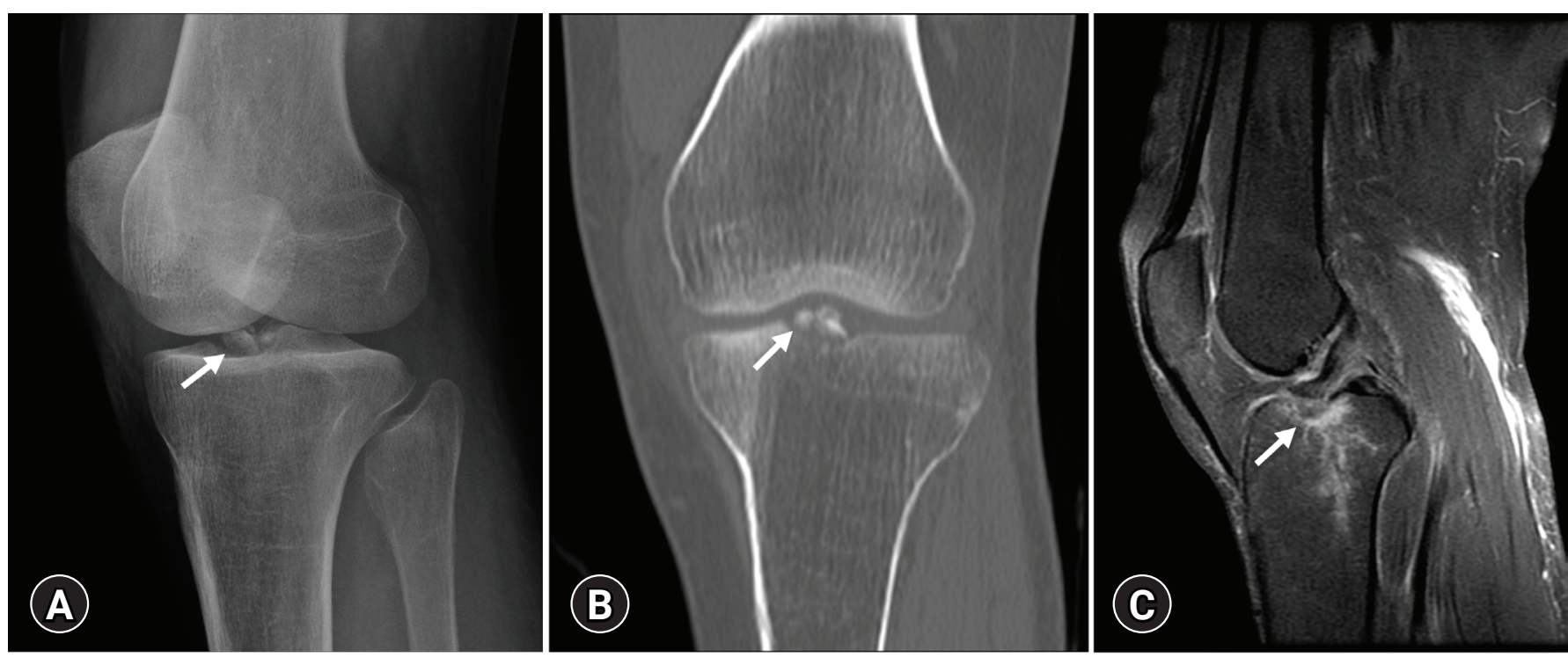

Fig. 9. Avulsion of the tibial eminence in a 45-year-old woman with acute pain and anterior instability of the knee. (A) The oblique radiograph and (B) the coronal computed tomography image of the knee show a bone fragment (arrow) that arises from the attachment site for the anterior cruciate ligament (ACL). (C) The sagittal fast spin-echo proton density-weighted magnetic resonance image with fat saturation reveals a bone fragment avulsed from the tibia with an intact ACL and adjacent marrow edema (arrow). Provided by Inje University Busan Paik Hospital. 

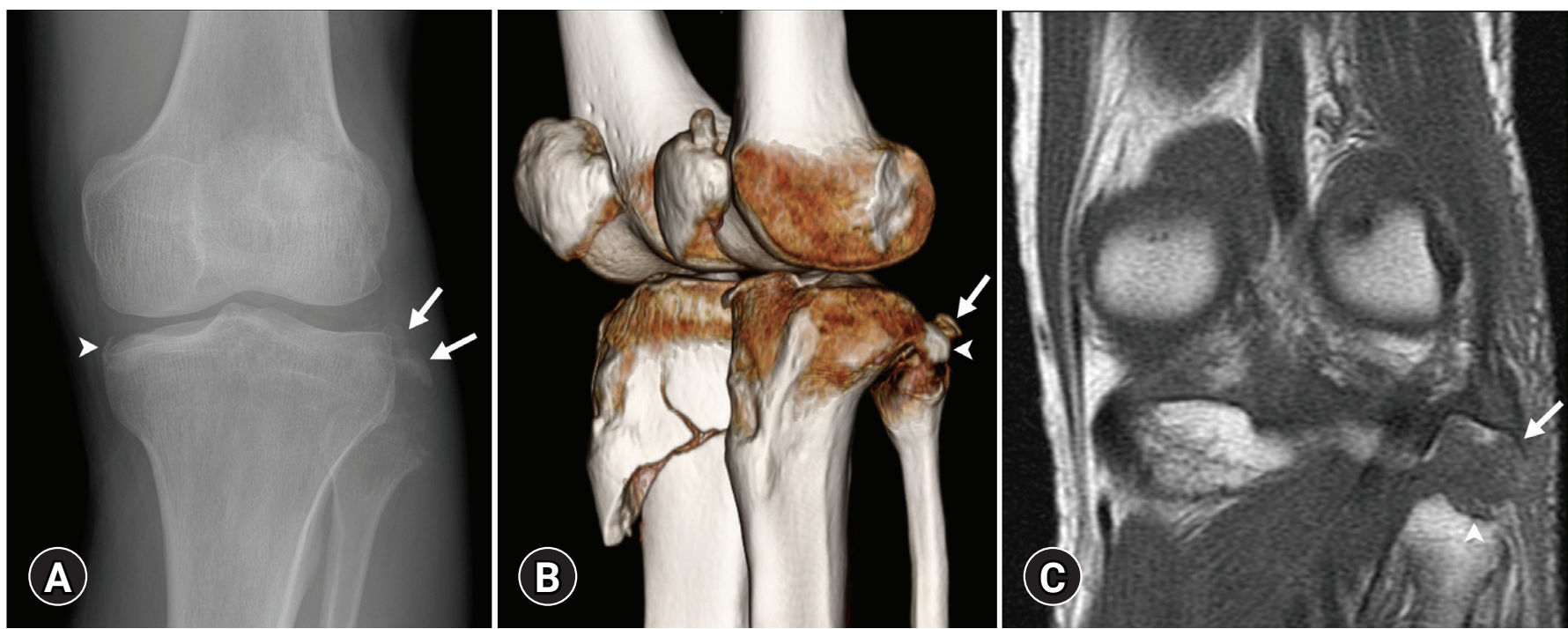

Fig. 10. Avulsion of the arcuate complex in a 36-year-old man who had a car accident. (A) The anteroposterior radiograph of the knee shows two small bone fragments (arrows) arising from the fibular head. Another elliptic bone fragment (arrowhead) arises from the medial tibial plateau, which represents an avulsion of the deep capsular component of the medial collateral ligament (reverse Segond fracture). (B) The three-dimensional volume-rendered computed tomography image shows two combined avulsion fractures of the arcuate complex (arrow) and the conjoined tendon of the lateral collateral ligament and the long head of the biceps femoris (arrowhead). The right proximal tibia has a fracture. (C) The coronal T1-weighted magnetic resonance image shows the avulsion of the arcuate complex (arrow) from the styloid process of the fibular head (the arcuate sign). Irregularity of the donor site from the fibular head is also seen (arrowhead). Provided by Inje University Busan Paik Hospital.

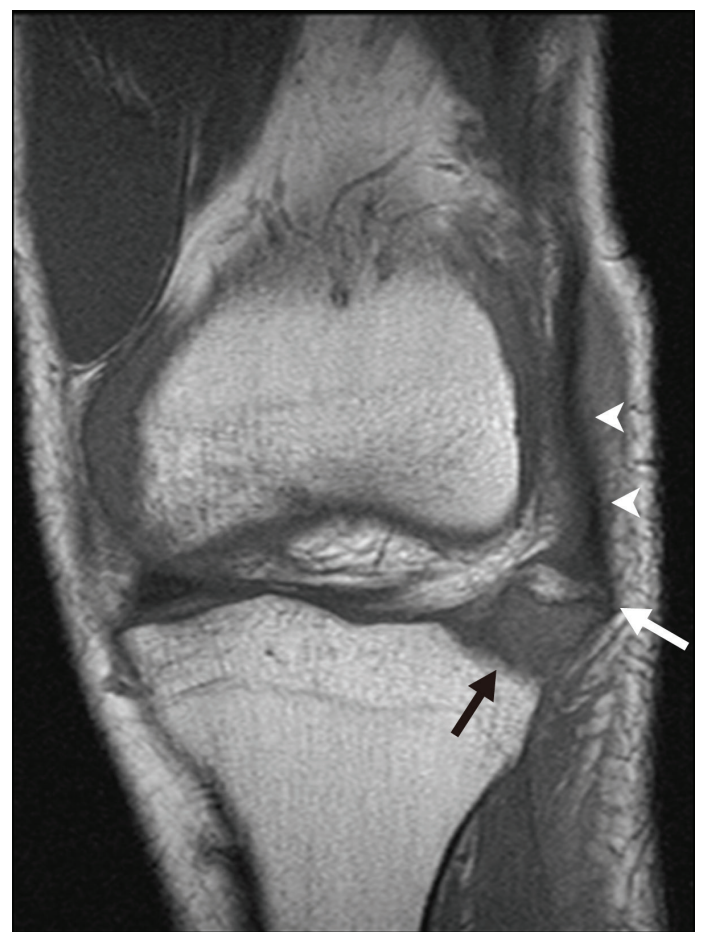

Fig. 11. Avulsion of the iliotibial band in a 40-year-old man who had a car accident. The coronal T1-weighted magnetic resonance image shows a bone fragment (white arrow) at the anterolateral aspect of the lateral tibial plateau, which is the attachment site for the iliotibial tract (arrowheads). Irregularity of the donor site from the lateral tibial cortex is also seen (black arrow). Provided by Inje University Busan Paik Hospital.

\section{Patellar tendon avulsion fracture}

1) Proximal patellar tendon avulsion fracture

Avulsion injuries of the inferior pole of the patella and the proximal patellar tendon include a wide spectrum that consists of “jumper's knee," patellar sleeve avulsion, and Sinding-Larsen-Johansson syndrome. The inferior pole of the patella is the origin of the patellar tendon, which inserts into the tibial tuberosity [30]. These injuries result from excessive quadriceps contraction against resistance, which can occur in basketball, volleyball, and football. "Jumper's knee" is the thickening of the patellar tendon but without demonstrable avulsion or tear. Patellar sleeve avulsion is an injury to the cartilaginous portion of the inferior pole of the patella, whereas Sinding-Larsen-Johansson syndrome is a pure osseous injury without cartilaginous injury (Fig. 12). On plain radiographs, these injuries appear similar to small bone fragments at the inferior pole of the patella. To differentiate between the two entities, MRI is required that reveals extensive cartilaginous or pure osseous injury at the inferior pole of the patella [49]. Treatments for displaced patellar sleeve avulsion include open reduction and internal fixation with reconstruction of the extensor apparatus, whereas minimally displaced fractures in Sinding-Larsen-Johansson syndrome are usually treated conservatively [49, $50]$. 


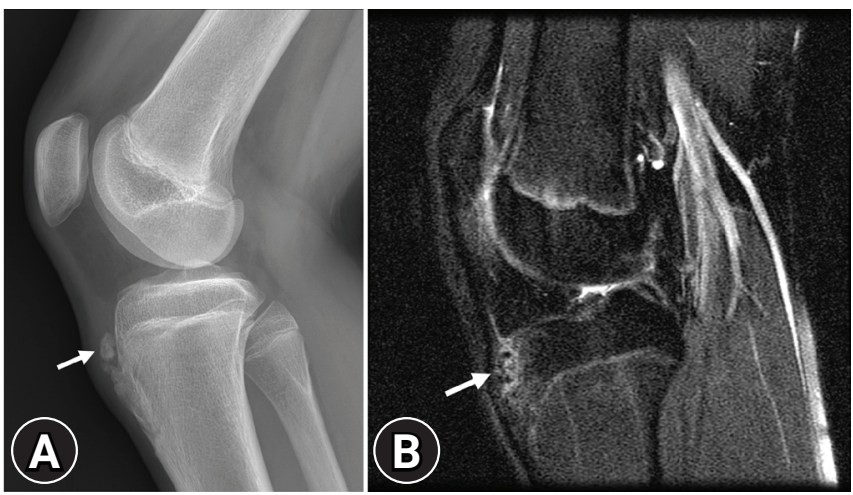

Fig. 12. Sinding-Larsen-Johansson syndrome in a 10-year-old boy with chronic knee pain. (A) The lateral radiograph of the knee shows a small bone fragment (arrow) at the inferior pole of the patella. (B) The sagittal T2-weighted magnetic resonance image with fat saturation reveals mild edema at the inferior pole of the patella (arrow). Provided by Inje University Busan Paik Hospital.

\section{2) Distal patellar tendon avulsion fracture}

The tibial tubercle is the insertion site of the patellar tendon. Avulsion injuries of the tibial tubercle are infrequent fractures that affect physically active adolescents. Injuries are associated with active extension of the knee and excessive contraction of the quadriceps muscles during jumping sports. Osgood-Schlatter disease may predispose to avulsion fracture of the tibial tubercle [51]. Diagnosis is primarily based on conventional radiography. Oblique radiographs of the proximal tibia and CT are useful for better recognition of the tubercle and fracture pattern $[51,52]$. MRI is helpful for assessing associated meniscal and ligament injuries.

Osgood-Schlatter disease is a traction apophysitis that results from repetitive microtrauma and traction on the tibial tubercle by the patellar tendon. The entity frequently occurs in active male adolescents who participate in sports that require jumping, squatting, and kicking [30]. On plain radiographs, bony fragments of the tibial tubercle and soft tissue swelling of the anterior aspect of the knee can be detected. Fragmentation of the tibial tubercle alone can mimic normal ossification centers in patients; therefore, MRI is required [53]. MRI can be helpful for confirming this diagnosis, which includes thickening of the infrapatellar tendon, soft-tissue swelling, obliteration of the inferior angle of the infrapatellar fat pad, and bony edema at the proximal tibia contiguous to the tibial tubercle (Fig. 13) [54]. The condition is self-limiting, and complete recovery is usually expected with the closure of the tibial growth plate $[54,55]$.

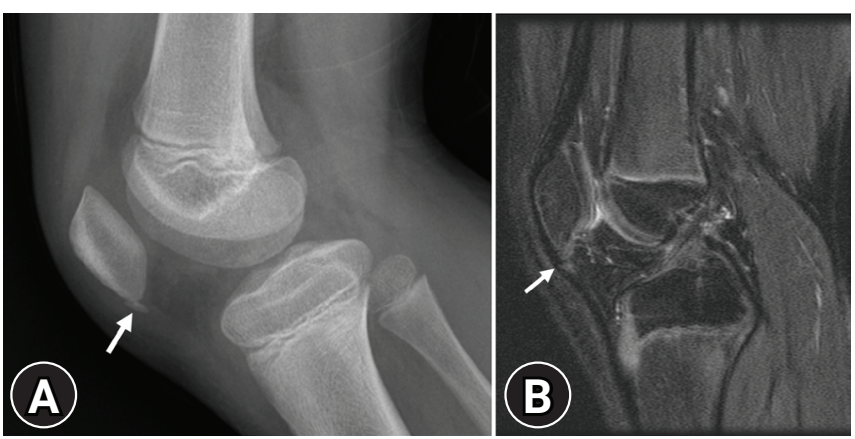

Fig. 13. Osgood-Schlatter disease in a 12-year-old boy with pain in the anterior knee for 3 years, who had jumped frequently. (A) The lateral radiograph of the knee shows several bone fragments (arrow) adjacent to the tibial tuberosity. (B) The sagittal T2weighted magnetic resonance image with fat saturation reveals several bone fragments with adjacent edema (arrow) around the tibial tuberosity. Provided by Inje University Busan Paik Hospital.

\section{Ankle and foot avulsion injuries}

\section{Fifth metatarsal base avulsion fracture}

An avulsion fracture of the fifth metatarsal base is a common lower extremity fracture. A forceful pull on the strong structures formed by the short peroneal muscle tendon while applying plantar flexion and ankle inversion on the foot (e.g., unstable landing after jumping or inverted ankle during running) is an important factor in this type of fracture [56]. Some authors have suggested that lateral slip of the plantar fascia is the most important structure involved in this injury [57]. It is important to differentiate this fracture from a Jones fracture, which is a transverse fracture through the junction of the diaphysis and metaphysis without distal extension into the intermetatarsal articulation, and a diaphyseal stress fracture, which occurs within the proximal $1.5 \mathrm{~cm}$ of the fifth metadiaphyseal junction because the treatment plan and prognosis for these conditions are different (Fig. 14) [58]. It has been traditionally believed that a Jones fracture and diaphyseal stress may require aggressive treatment. A recent review recommends that an avulsion fracture of the fifth metatarsal base and a Jones fracture should be treated functionally, but diaphyseal stress seems to benefit from early intramedullary screw fixation $[59,60]$.

\section{Achilles tendon avulsion fracture}

An avulsion fracture of the calcaneal tuberosity is a rare fracture that occurs at the posterosuperior aspect of the calcaneus because of a pull on the Achilles tendon. This injury can occur in patients with osteoporosis and neuropathic disorders (e.g., diabetes mellitus) or can occur due to trauma that causes dorsiflexion of the foot [61]. There are four types of calcaneal avulsion fractures: 
type I, simple extra-articular avulsion fracture; type II, "beak" fracture with an oblique fracture line running posterior; type III, infrabursal avulsion fracture involving superficial fibers of the Achilles tendon; type IV, small beak fracture involving the deep fibers of the Achilles tendon [62]. MRI may be helpful for confirmation of type III and IV fractures because it can discriminate be-

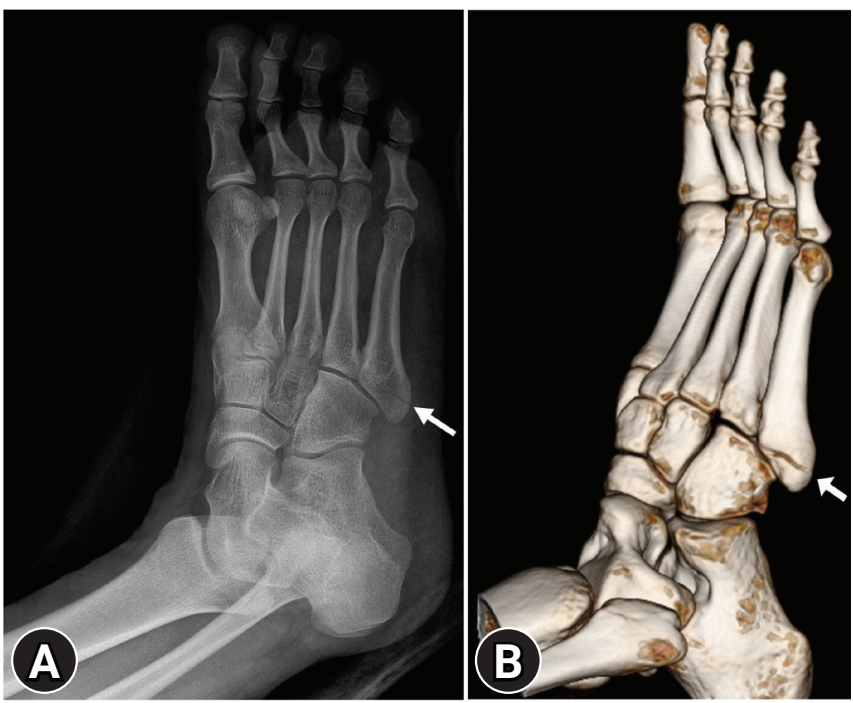

Fig. 14. Avulsion fracture of the fifth metatarsal base in a 16-yearold girl with midfoot pain for 1 day. (A) The oblique radiograph of the foot and (B) the three-dimensional volume-rendered computed tomography image show a non-displaced avulsion fracture (arrow) at the tuberosity of the fifth metatarsal base. Provided by Inje University Busan Paik Hospital. tween superficial and deep fibers of the tendon. Type I fractures are insufficiency fractures that usually occur as a result of minor trauma such as tripping in elderly patients with osteoporosis. These fractures displace the avulsed fragment superiorly (Fig. 15). However, type III and IV fractures mainly occur in younger patients with severe trauma, such as falling down $[62,63]$. Treatment options depend on fracture type. Patients with type II fractures are at risk of severe wound complications, such as skin necrosis. Therefore, careful examination of the posterior skin of the heel and urgent reduction with fixation are required if the skin is tented or appears blanched [62].

\section{Talar anterior capsular avulsion fracture}

Fractures of the talus are generally believed to be relatively uncommon. However, these fractures are the second most common fracture of the tarsal bone. Improved recognition has resulted in an increased number of talar process fractures being diagnosed [64]. Anterior capsular avulsion occurs in basketball players and is a chronic injury caused by microtrauma [1]. A lateral radiograph easily shows a bony protuberance in the concavity of the dorsal talus, corresponding to a cortical avulsion of the broad insertion of the talonavicular joint capsule (Fig. 16).

\section{Superior peroneal retinacular avulsion fracture}

The superior peroneal retinaculum constitutes the posterolateral border of the peroneal tunnel, thus preventing the displacement of the peroneal tendons [65]. Sudden dorsiflexion of the
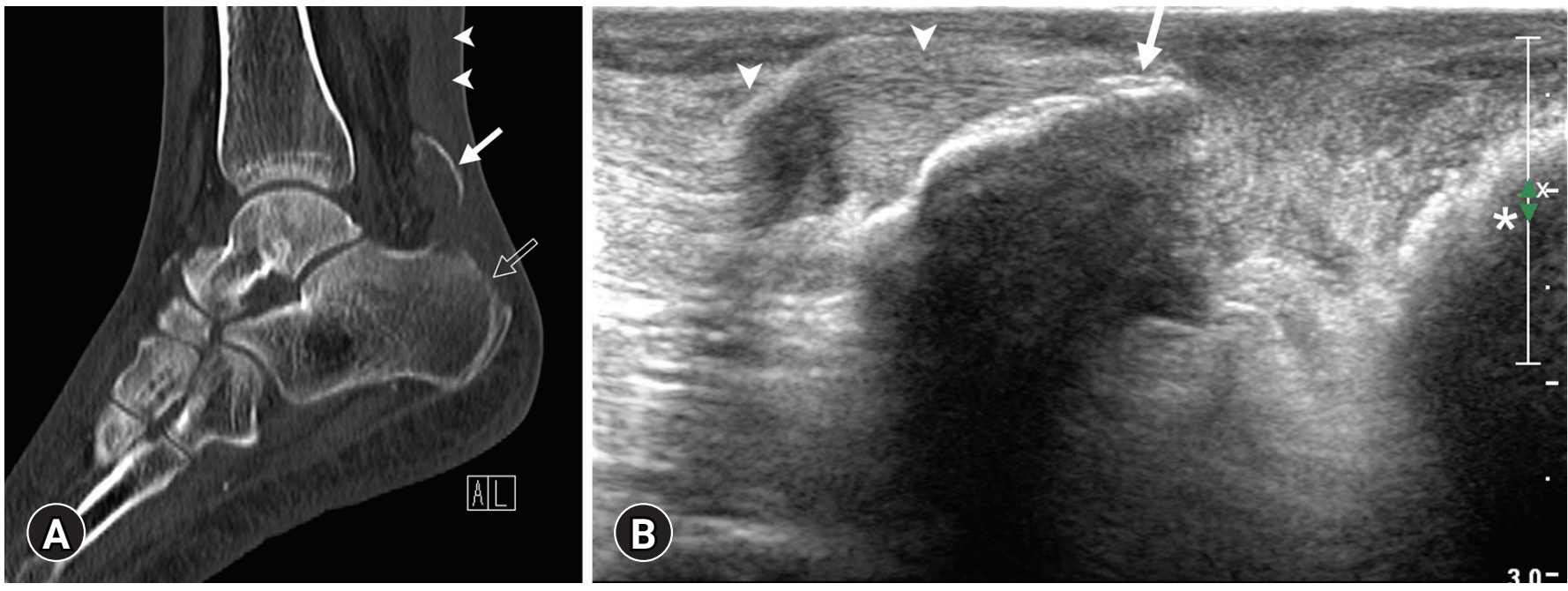

Fig. 15. Avulsion of the calcaneal tuberosity in a 44-year-old woman with diabetes mellitus. (A) The sagittal computed tomography image of the ankle shows an avulsion fracture of the calcaneal tuberosity (arrow), which is the attachment site of the Achilles tendon (arrowheads). The bone fragment is sharply defined and displaced superiorly. The donor site of the calcaneus is also irregular (open arrow). (B) The longitudinal ultrasonography image of the ankle in the prone position depicts a bone fragment (arrow) arising from the calcaneus (asterisk) with mild cephalad displacement. A retracted Achilles tendon (arrowheads) is also seen. Provided by Inje University Busan Paik Hospital. 

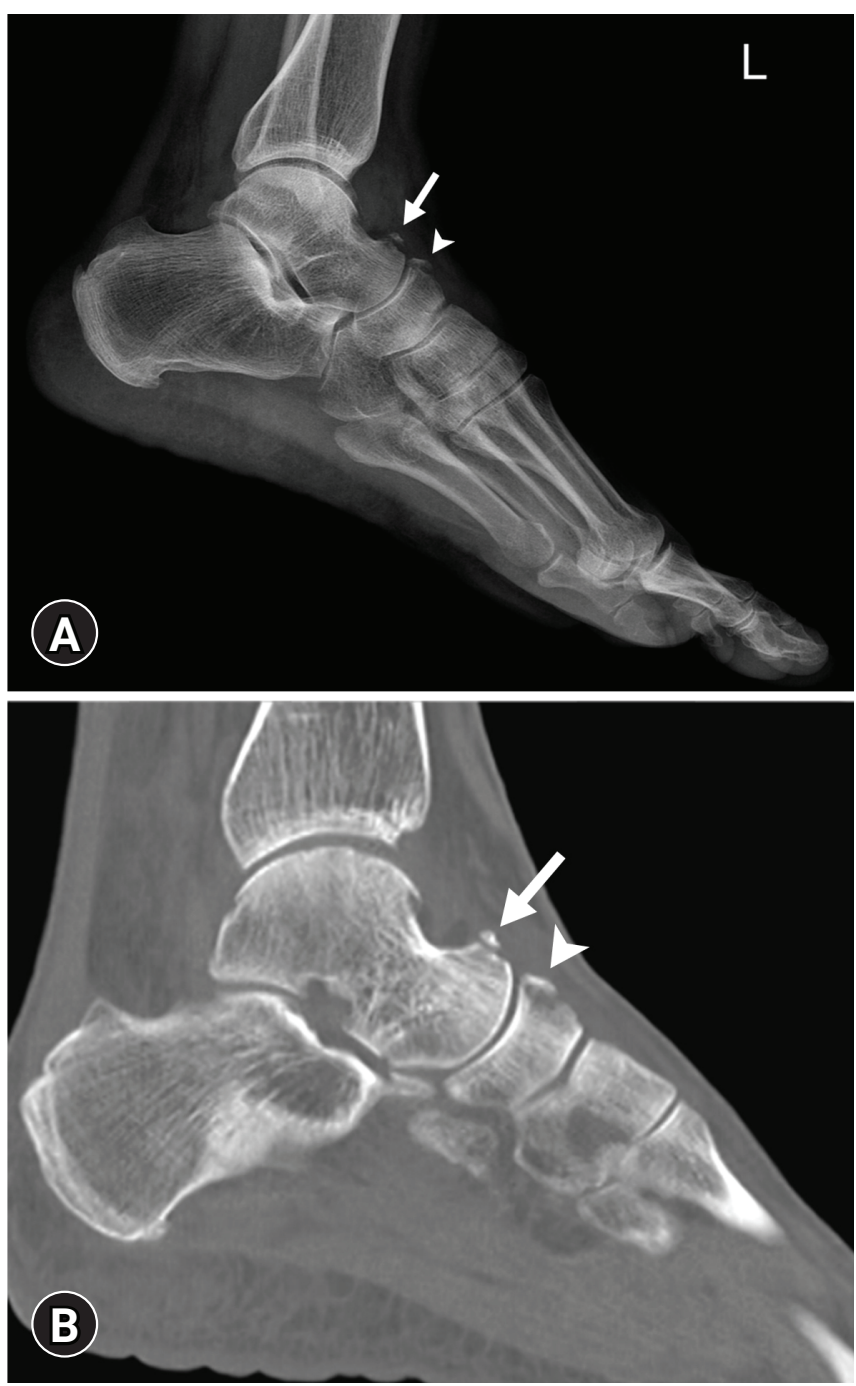

Fig. 16. Anterior capsular avulsion of the ankle in a 45-yearold man with chronic pain in the proximal anterior foot. (A) The lateral radiograph of the ankle and (B) the sagittal computed tomography image show an elliptic tiny bone fragment (arrow) adjacent to the anterior talus, which is the attachment site of the joint capsule. Another avulsion fracture of the navicular bone (arrowhead) is present where the talonavicular ligament is attached. Provided by Inje University Busan Paik Hospital.

foot occurring simultaneously with violent contraction of the peroneal muscles can cause a distal fibular avulsion fracture at the attachment of the retinaculum to the lateral malleolus. Radiographs and CT imaging can reveal small linear bony fragments along the lateral margin of the distal fibula. MRI can depict bony fragments and bone marrow edema, as well as subluxation or dislocation of the peroneal tendons (Fig. 17). Nonoperative plaster immobilization is initially attempted; however, surgery may be required for patients with painful, chronic, or unstable dislocations [66].
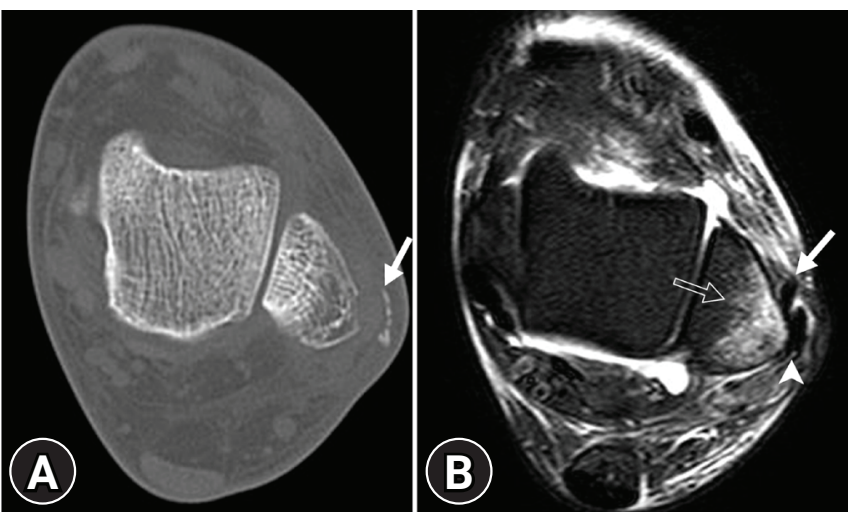

Fig. 17. Avulsion of the superior peroneal retinaculum in a 27-year-old man with left ankle pain for 3 days, after spraining the ankle during skiing. (A) The axial computed tomography image shows a linear bone fragment (arrow) arising from the lateral margin of the distal fibula. There is soft tissue density between the bone fragment and the lateral malleolus. The normal peroneal tendons are not visible in the retromalleolar groove. (B) The axial T2-weighted magnetic resonance image with fat saturation reveals that the peroneus brevis (arrow) and longus (arrowhead) tendons are lateral to the lateral margin of the fibula, which represents the complete rupture of the superior peroneal retinaculum. Bone marrow edema of the lateral aspect of the distal fibula (open arrow) is also present. Provided by Inje University Busan Paik Hospital.

\section{Shoulder avulsion injuries}

\section{Greater tuberosity avulsion fracture}

Isolated humeral avulsion fractures are rare in the greater tuberosity, which is the attachment site of rotator cuff muscles such as the supraspinatus, infraspinatus, and teres minor tendons. This injury can occur as a result of an extreme pull on the external rotators, after the abduction and external rotation of the arm, after a direct blow to the lateral aspect of the shoulder, after a fall on an outstretched hand with the elbow in full extension or flexion, or after a seizure [67]. The differential diagnosis of this injury is crucial but difficult. Patients with this injury present with decreased abduction strength that mimics rotator cuff injury, which requires prompt surgical repair. However, non-displaced avulsion injuries of the greater tuberosity tend to respond well to conservative treatments, such as immobilization. On plain radiographs, these fractures may be challenging to identify because of osseous overlap. Additional anteroposterior views with internal and external rotation can provide more details regarding a fracture of the greater tuberosity and help identify an occult non-displaced surgical neck fracture [68]. US can be helpful in detecting cortical step-off, which indicates avulsion injury of the greater tuberosity [1]. In patients with clinically suspected rotator cuff injuries, MRI can occasionally show edema at the greater tu- 
berosity with occult non-displaced avulsion fractures (Fig 18); MRI can also distinguish rotator cuff injuries from articular injuries.

\section{Lesser tuberosity avulsion fracture}

Isolated avulsion fracture of the lesser tuberosity is an uncommon injury that may cause significant disability if not diagnosed appropriately. The lesser tuberosity is the attachment site of the subscapularis muscle and tendon. Forceful contraction of the subscapularis muscle to resist abduction and external rotation of the shoulder, and the resultant strong traction force avulses the lesser tuberosity. The most common cause of injury is muscular violence, but a sudden involuntary contraction of the subscapularis muscle during sleep, which may occur during electroconvulsive therapy for psychiatric disorders, may also result in this fracture [69]. An anteroposterior view in maximal internal rotation projecting the lesser tuberosity in the profile usually shows a large displaced fragment. An axillary view is sometimes needed to detect minimally displaced small fragments and is essential to prevent the injury. On plain radiographs, these fractures may be confused with calcific tendonitis of the rotator cuff or osseous Bankart lesions (Fig. 19) [70,71]. CT can properly show even minimally displaced small fragments. Although MRI is not necessary, it allows the evaluation of the entire rotator cuff and better visualization of a minimally displaced fragment [1]. Most acute cases are usually treated by open reduction and internal fixation, but acute non-displaced fractures are treated nonoperatively with satisfactory results. Operative treatment is recommended in patients with a displacement greater than $5 \mathrm{~mm}$ or $45^{\circ}$ of angulation, blockage of motion, significant clinical weakness, or continued pain [72].

\section{Elbow avulsion injuries}

Various mechanisms, such as high compressive-tensile loads, can lead to osseous or chondral avulsion injuries.

\section{Little Leaguer's elbow}

The medial epicondyle is the most common site of avulsion injury in the elbow. Before fusion, valgus overload to the medial elbow structures primarily affects the physis, rather than the MCL. Little Leaguer's elbow results from a chronic overuse injury of the medial epicondyle in skeletally immature throwing athletes (i.e., pitchers) [73]. The initial radiographic evaluation may be normal in up to $85 \%$ of the patients. Radiographs may show displacement and fragmentation of the medial epicondyle apophysis. Epicondylar overgrowth resulting from chronic traction injury and adjacent
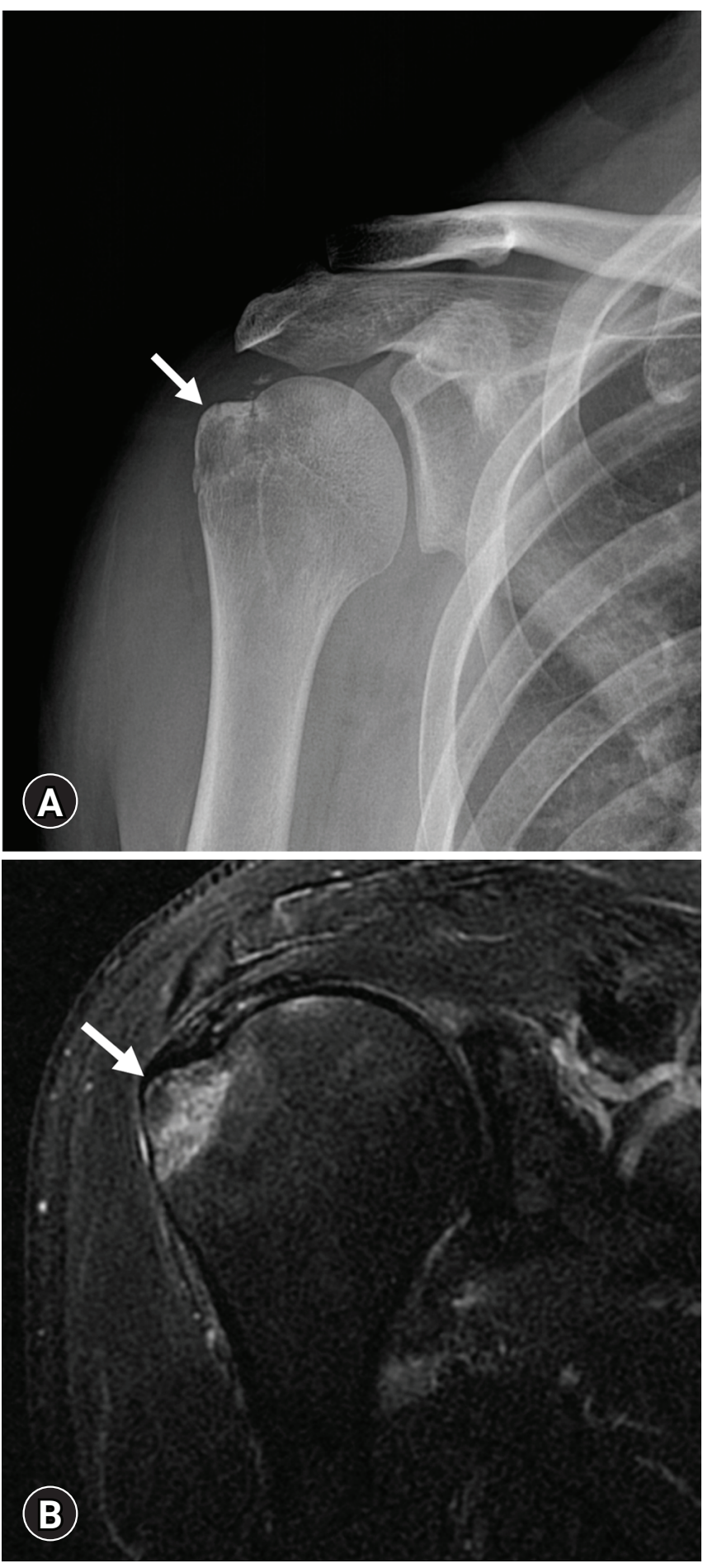

Fig. 18. An avulsion fracture of the greater tuberosity in a 30-year-old man who experienced shoulder pain after falling. (A) The anteroposterior radiograph of the shoulder shows an avulsion fracture of the greater tuberosity (arrow). (B) The coronal T2weighted magnetic resonance image with fat saturation reveals marrow edema of the greater tuberosity (arrow). The rotator cuff is intact. Provided by Inje University Busan Paik Hospital. 


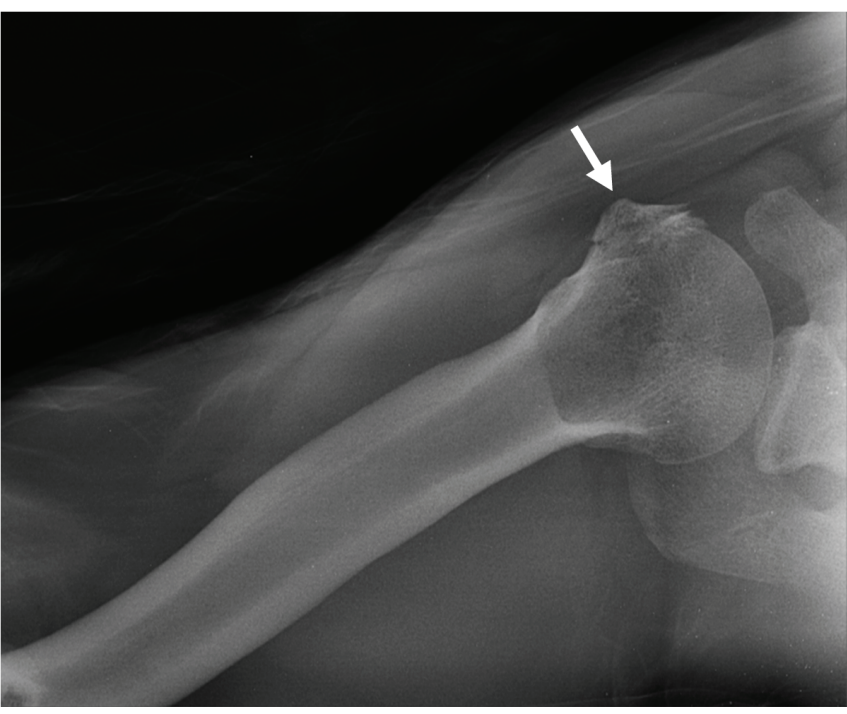

Fig. 19. An avulsion fracture of the lesser tuberosity in a 34-year-man who had fallen from a 7 meter high building. The axillary radiograph of the shoulder shows an avulsion fracture of the lesser tuberosity (arrow). Provided by Inje University Busan Paik Hospital.

soft tissue swelling can be observed [74]. MRI can show physeal irregularity or widening between the medial epicondyle and distal humerus and bone marrow edema (Fig. 20). The common flexor tendon may also be thickened [74]. The first line of treatment includes rest from the activity for 4 to 6 weeks and analgesics. Strengthening exercises and physical therapy are also recommended, followed by an interval throwing program [75].

\section{Olecranon process avulsion fracture}

Avulsion fracture of the olecranon process of the ulna, which is the attachment site of the triceps tendon, is a relatively rare injury, but may be associated with fracture of the radial head [76]. This injury may occur after forceful contraction of the triceps during a fall with an outstretched arm. Radiographs can show a bony fragment that is non-displaced or proximally displaced at the posterior aspect of the proximal ulna. CT can more definitively depict small osseous fragments at the posterior aspect of the proximal ulna. MRI can show a signal change in the triceps tendon and the surrounding soft tissue. Avulsion fractures of the olecranon process should be differentiated from the os supratrochlear dorsale, an accessory ossicle of the elbow. Plate fixation or excision of the fragment with triceps advancement is necessary for most patients. Nonoperative management is not indicated in this injury. Fractures of the olecranon generally have a favorable prognosis after treatment; an estimated $96 \%$ of patients have good to excellent long-term outcomes, with only rare cases showing adverse events [77].

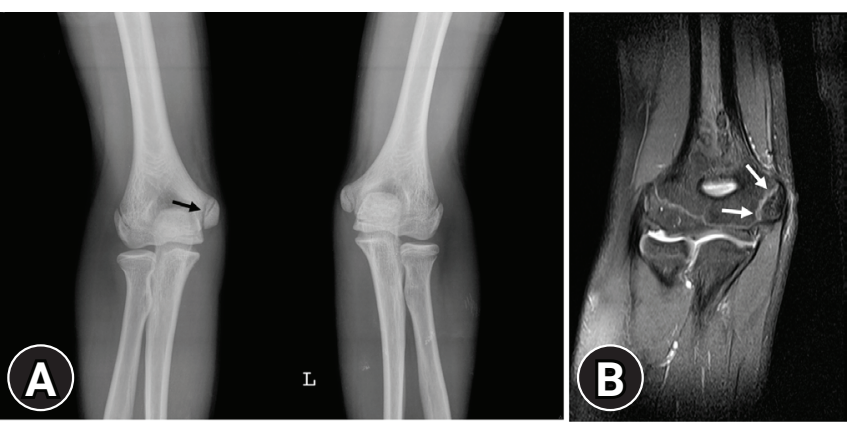

Fig. 20. Little League elbow in a 14-year-old baseball pitcher with elbow pain for 3 months. (A) The anteroposterior radiograph of both elbows shows a mild widening of the medial epicondylar physis (arrow). (B) The coronal T2-weighted magnetic resonance image with fat saturation shows widening of the medial epicondylar physis, which is surrounded by increased T2 signal intensity due to edema (arrows). Provided by Pusan National University Hospital.

\section{Medial epicondyle avulsion fracture}

Acute traumatic avulsion fractures of the medial epicondyle occur primarily in boys between the ages of 9 and 14 years; however, it has also been described in adolescents. This injury may occur after a vigorous valgus force of the elbow with simultaneous forearm flexion [78]. Approximately half of medial epicondyle fractures are associated with posterolateral dislocation of the elbow, and often the avulsed fragment becomes trapped within the joint $[1,78]$. Medial epicondyle avulsion fractures are of two distinct types. Type 1 lesions occur in younger patients and are characterized by a large fragment typically involving the entire epicondyle. Type 2 lesions occur in adolescents and produce small fragments. MRI is better for evaluating non-ossified medial epicondylar avulsion fractures [79]. Radiographs and CT imaging show an irregular lucent area, fragmentation or separation of the medial epicondyle, and an apophyseal fragment that can be entrapped in the joint capsule (Fig. 21). In general, less than $1 \mathrm{~cm}$ of displacement responds well to conservative treatment, whereas displaced fractures or fractures with an incarcerated fragment are treated by open reduction and screw fixation. Operative options also allow for exploration of ulnar nerve injuries $[80,81]$.

\section{Hand avulsion injuries}

There are several avulsion injuries of the hand and wrist. They have characteristic imaging features and injury mechanisms.

\section{Volar plate avulsion fracture}

A volar plate avulsion fracture is a common injury that occurs at the proximal interphalangeal joint. The volar plate is a fibrocarti- 
laginous structure that is attached to the base of the middle phalanx distal to the joint and prevents hyperextension. Volar plate avulsion fractures typically occur when forceful hyperextension is applied to the fingertip, especially during ball-handling sports [82]. Radiographs show a small fragment of bone avulsed from the volar aspect of the base of the middle phalanx. US can show

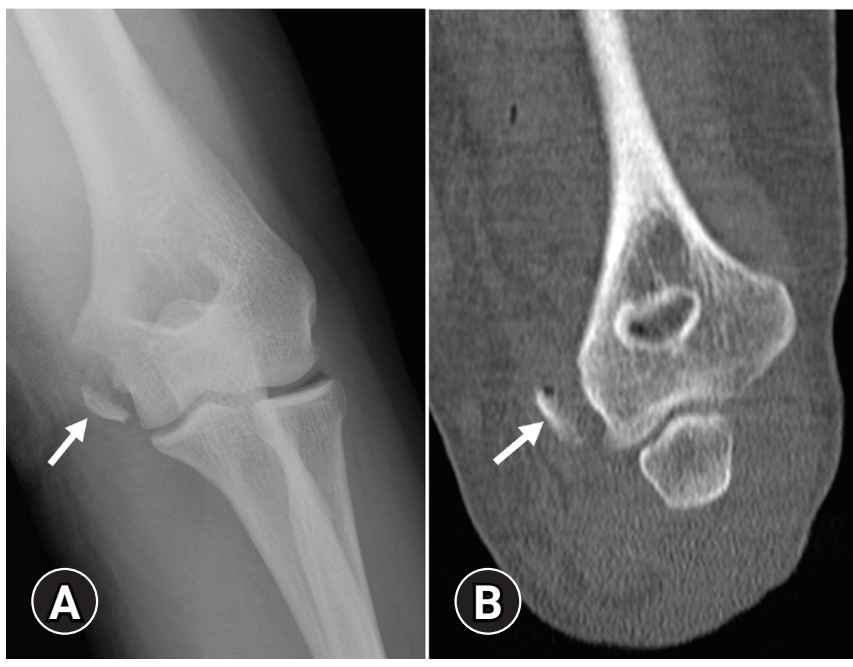

Fig. 21. An avulsion fracture of the olecranon in a 64-yearold-woman who experienced elbow pain after falling. (A) The lateral radiograph of the elbow and (B) the sagittal computed tomography image show an avulsion fracture of the olecranon (arrow). Provided by Pusan National University Hospital. small bony fragments and adjacent fluid collection at the volar aspect of the base of the middle phalanx. MRI can more definitively depict bone and soft tissue edema and adjacent fluid collection (Fig. 22). Treatment options are conservative and range from early active motion with or without buddy strapping to immobilization at various degrees of flexion/extension [83].

\section{Skier's thumb}

Avulsion injury involving the ulnar collateral ligament of the first metacarpal joint is a frequent injury that is called "skier's thumb" or "gamekeeper's thumb." This condition is termed "gamekeeper's thumb" because the injury is a common chronic occupational injury occurring in British gamekeepers. However, it is more commonly encountered in athletes, especially as an acute injury in skiers; therefore called "skier's thumb” nowadays [84]. It occurs after violent hyperabduction of the metacarpophalangeal joint. It is more likely to occur if the thumb is simultaneously gripping something. Radiographs may be normal or show a small fragment at the base of the proximal phalanx of thumb; MRI can show abnormally high signal intensity at the base of the proximal phalanx of thumb, which is the distal attachment site of the ulnar collateral ligament (Fig. 23). Nonoperative treatment such as metacarpophalangeal joint immobilization is suggested, but surgical treatment is recommended for a Stener lesion, which occurs when the aponeurosis of the adductor pollicis muscle is interposed between the ruptured ulnar collateral ligament of the thumb and its site of
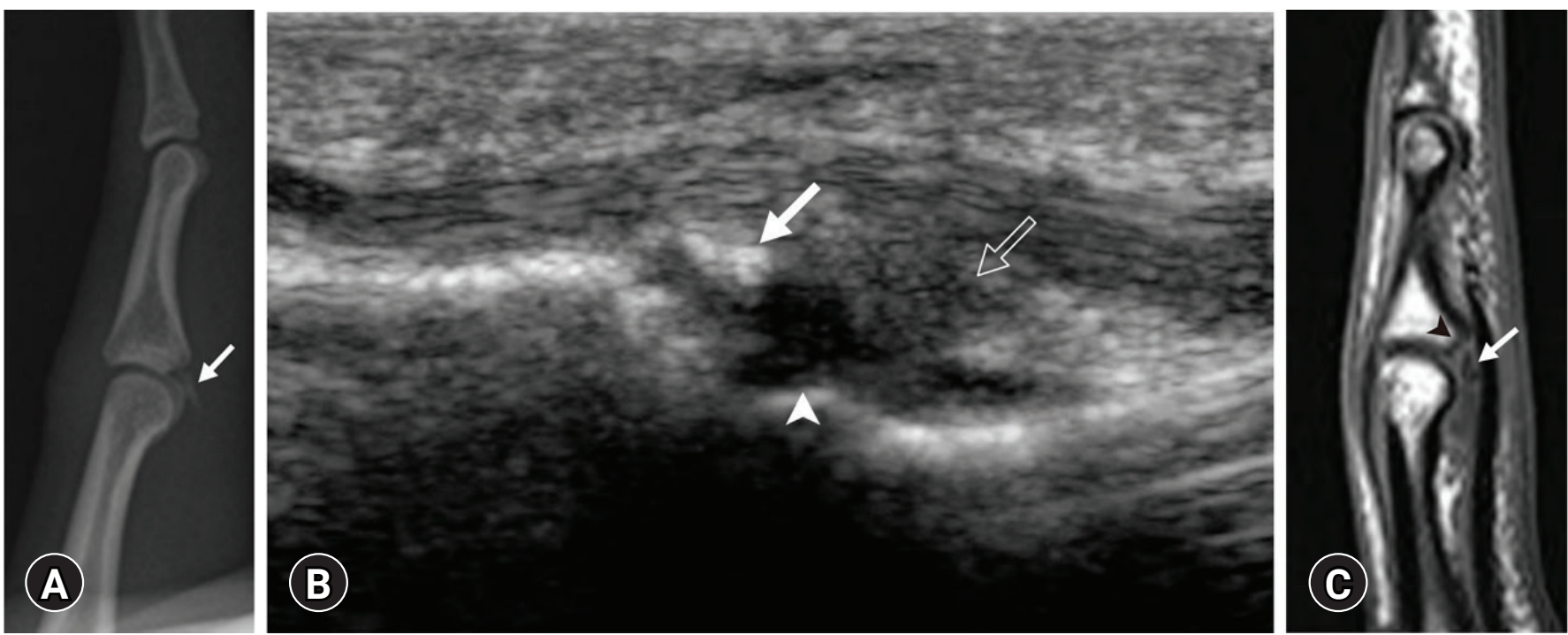

Fig. 22. An avulsion fracture of the volar plate in a 20-year-old handball player with acute pain in the second finger after a hyperextension injury. (A) The lateral radiograph of the second finger shows a small bone fragment (arrow) arising from the volar aspect of the base of the middle phalanx. (B) The longitudinal ultrasonography image shows a small bone fragment (arrow) and adjacent fluid collection (arrowhead) at the volar aspect of the base of the middle phalanx. The volar plate is deformed and it has low echogenicity (open arrow). (C) The sagittal T1-weighted magnetic resonance image shows an avulsion fracture of the volar plate (arrow). Irregularity of the donor site from the base of the middle phalanx is also seen (arrowhead). Provided by Inje University Busan Paik Hospital. 


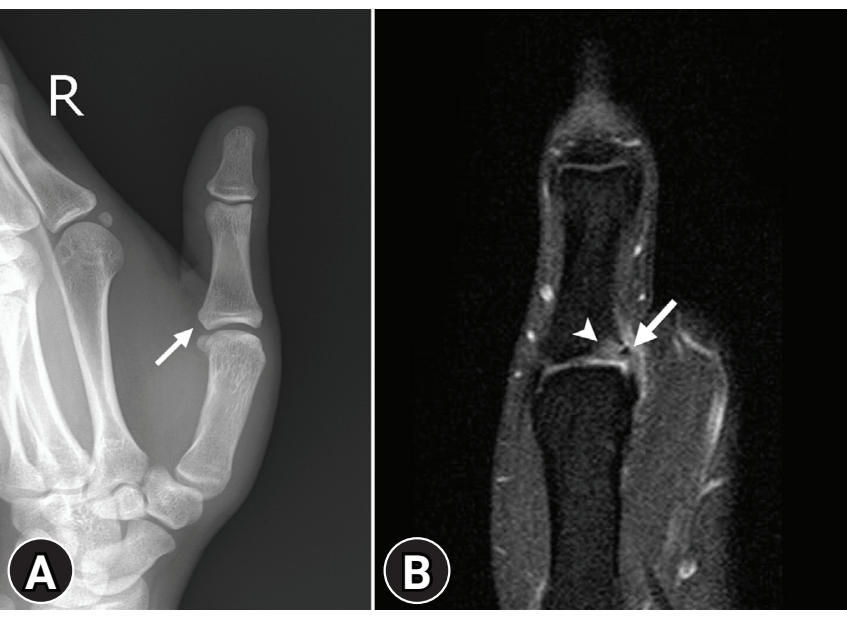

Fig. 23. Skier's thumb in a 19-year-old skier with acute pain in the thumb. (A) The anteroposterior radiograph of the thumb shows a tiny bone fragment adjacent to the base of the proximal phalanx. (B) The coronal contrast-enhanced T1-weighted magnetic resonance image shows an avulsion fracture of the distal ulnar collateral ligament (arrow) with adjacent marrow edema (arrowhead). Provided by Inje University Busan Paik Hospital.

insertion at the base of the proximal phalanx [85].

\section{Mallet finger}

Mallet finger is a common closed tendon injury that accounts for $2 \%$ of all sporting injuries [86]. It occurs when a forceful blow is applied to the tip of the finger, causing a sudden flexion or hyperextension injury. It manifests as an extensor tendon rupture at the insertion site or as an avulsion fracture involving the insertion of the terminal extensor tendon $[86,87]$. If there is a bony avulsion, radiologic findings of the mallet finger would classically be the presence of a triangular avulsion fragment at the extensor aspect of the distal phalanx at the distal interphalangeal joint (Fig. 24). MRI may show disruption of the extensor tendon in patients without a bony avulsion fragment. The recommended treatment for most mallet finger injuries is the immobilization of the distal interphalangeal joint held in extension by splints. Surgical treatment is only considered in cases of open injuries, failed to splint, palmar subluxation of the distal phalanx, or a large displaced articular fracture fragment greater than one-third of the joint surface [88]. If it is untreated, a swan neck deformity or secondary osteoarthritic changes may develop.

\section{Conclusion}

Although diverse avulsion injuries occur in all age groups, they primarily affect skeletally immature athletes. These injuries can

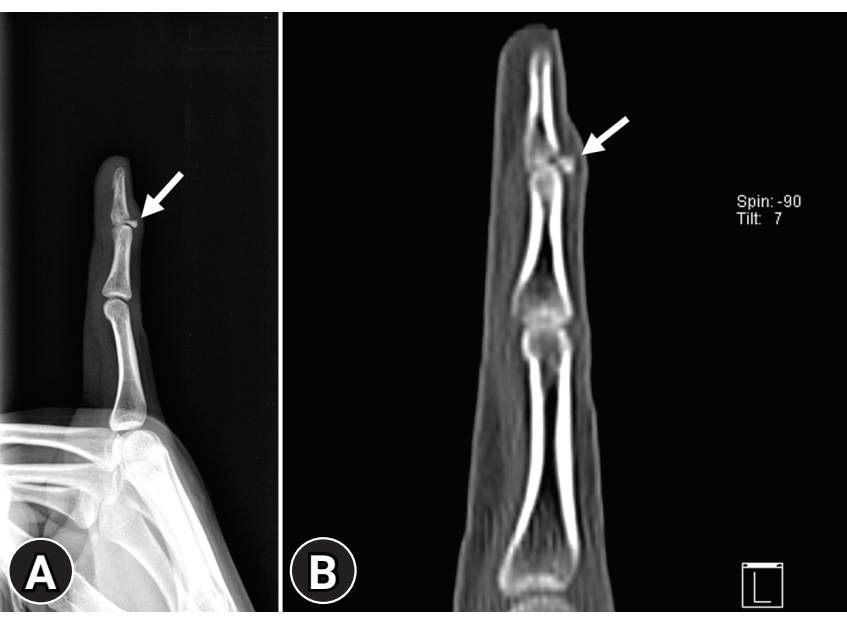

Fig. 24. Mallet finger in a 26-year-old basketball player with acute pain in the fifth finger. (A) The lateral radiograph of the fifth finger and (B) the sagittal computed tomography image show a triangular bone fragment (arrow) at the extensor aspect of the distal phalanx that is adjacent to the distal interphalangeal joint. Provided by Inje University Busan Paik Hospital.

mimic more serious conditions, such as infection or neoplasm, because of a variety of imaging findings associated with different stages and mechanisms. Conventional radiography is the first imaging modality used to diagnose avulsion injury. In certain cases showing subtle appearances on radiographs, advanced imaging modalities are helpful and can provide additional information to appropriately define the extent of the damage. US has a high spatial resolution with a dynamic assessment potential and allows comparison with the opposite side. CT is more sensitive for depicting a tiny osseous fragment located adjacent to the expected attachment site of a ligament, tendon, or capsule. MRI is the best imaging modality for identifying edematous changes in bone and soft tissue that help radiologists detect the affected muscles, tendons, ligaments, and associated bony lesions. An understanding of the vulnerable sites and pathophysiology of avulsion injuries allows accurate diagnosis and appropriate patient management.

\section{Notes}

\section{Conflicts of interest}

No potential conflict of interest relevant to this article was reported.

\section{Funding}

This work was supported by the 2019 Inje University research grant. 


\section{Author contributions}

Conceptualization: CC, SJL, HJC, ISL; Data curation: CC, SJL; Formal analysis: CC, SJL, HJC, SKK, ISL; Funding acquisition: SJL; Methodology: HJC, SKK; Project administration: SKK, ISL; Supervision: SJL; Writing - original draft: CC; Writing - review \& editing: SJL, HJC, SKK, ISL.

\section{ORCID}

Changwon Choi, https://orcid.org/0000-0003-4080-6781

Sun Joo Lee, https://orcid.org/0000-0001-6210-9720

Hye Jung Choo, https:/ /orcid.org/0000-0003-3941-6989

In Sook Lee, https://orcid.org/0000-0001-7295-600X

Sung Kwan Kim, https://orcid.org/0000-0001-9459-3772

\section{References}

1. Stevens MA, El-Khoury GY, Kathol MH, Brandser EA, Chow S. Imaging features of avulsion injuries. Radiographics 1999;19: 655-72.

2. Squires B, Allen PE, Livingstone J, Atkins RM. Fractures of the tuberosity of the calcaneus. J Bone Joint Surg Br 2001;83:5561.

3. Sanders TG, Zlatkin MB. Avulsion injuries of the pelvis. Semin Musculoskelet Radiol 2008;12:42-53.

4. Vandervliet EJ, Vanhoenacker FM, Snoeckx A, Gielen JL, Van Dyck P, Parizel PM. Sports-related acute and chronic avulsion injuries in children and adolescents with special emphasis on tennis. Br J Sports Med 2007;41:827-31.

5. Lazović D, Wegner U, Peters G, Gossé F. Ultrasound for diagnosis of apophyseal injuries. Knee Surg Sports Traumatol Arthrosc 1996;3:234-7.

6. Fernbach SK, Willkinson RH. Avulsion injuries of the pelvis and proximal femur. Am J Roentgenol 1981;137:581-4.

7. Orava S, Ala-Ketola L. Avulsion fractures in athletes. Br J Sports Med 1977;11:65-71.

8. Metzmaker JN, Pappas AM. Avulsion fractures of the pelvis. Am J Sports Med 1985;13:349-58.

9. Rossi F, Dragoni S. Acute avulsion fractures of the pelvis in adolescent competitive athletes: prevalence, location and sports distribution of 203 cases collected. Skeletal Radiol 2001;30: $127-31$.

10. Abebe ES, Moorman CT, Garrett WE. Proximal hamstring avulsion injuries: injury mechanism, diagnosis and disease course. Oper Tech Sports Med 2012;20:2-6.

11. Wood DG, Packham I, Trikha SP, Linklater J. Avulsion of the proximal hamstring origin. J Bone Joint Surg Am 2008;90: 2365-74.
12. Brandser EA, el-Khoury GY, Kathol MH, Callaghan JJ, Tearse DS. Hamstring injuries: radiographic, conventional tomographic, CT, and MR imaging characteristics. Radiology 1995;197: 257-62.

13. Ferlic PW, Sadoghi P, Singer G, Kraus T, Eberl R. Treatment for ischial tuberosity avulsion fractures in adolescent athletes. Knee Surg Sports Traumatol Arthrosc 2014;22:893-7.

14. Schiller J, DeFroda S, Blood T. Lower extremity avulsion fractures in the pediatric and adolescent athlete. J Am Acad Orthop Surg 2017;25:251-9.

15. Singer G, Eberl R, Wegmann H, Marterer R, Kraus T, Sorantin E. Diagnosis and treatment of apophyseal injuries of the pelvis in adolescents. Semin Musculoskelet Radiol 2014;18:498-504.

16. Saluan PM, Weiker GG. Avulsion of the anterior inferior iliac spine. Orthopedics 1997;20:558-9.

17. Ouellette H, Thomas BJ, Nelson E, Torriani M. MR imaging of rectus femoris origin injuries. Skeletal Radiol 2006;35:665-72.

18. Rajasekhar C, Kumar KS, Bhamra MS. Avulsion fractures of the anterior inferior iliac spine: the case for surgical intervention. Int Orthop 2001;24:364-5.

19. Hébert KJ, Laor T, Divine JG, Emery KH, Wall EJ. MRI appearance of chronic stress injury of the iliac crest apophysis in adolescent athletes. Am J Roentgenol 2008;190:1487-91.

20. Steerman JG, Reeder MT, Udermann BE, Pettitt RW, Murray SR. Avulsion fracture of the iliac crest apophysis in a collegiate wrestler. Clin J Sport Med 2008;18:102-3.

21. Schlegel TF, Bushnell BD, Godfrey J, Boublik M. Success of nonoperative management of adductor longus tendon ruptures in National Football League athletes. Am J Sports Med 2009; 37:1394-9.

22. Ueblacker P, English B, Mueller-Wohlfahrt HW. Nonoperative treatment and return to play after complete proximal adductor avulsion in high-performance athletes. Knee Surg Sports Traumatol Arthrosc 2016;24:3927-33.

23. O’Rourke MR, Weinstein SL. Osteonecrosis following isolated avulsion fracture of the greater trochanter in children. A report of two cases. J Bone Joint Surg Am 2003;85:2000-5.

24. James SL, Davies AM. Atraumatic avulsion of the lesser trochanter as an indicator of tumour infiltration. Eur Radiol 2006;16: 512-4.

25. Theologis TN, Epps H, Latz K, Cole WG. Isolated fractures of the lesser trochanter in children. Injury 1997;28:363-4.

26. Freitas A, Macedo SL Sr. Apophyseal fracture or avulsion of the greater trochanter. Acta Ortop Bras 2016;24:164-6.

27. Weaver JS, Jacobson JA, Jamadar DA, Hayes CW. Sonographic findings of adductor insertion avulsion syndrome with magnetic resonance imaging correlation. J Ultrasound Med 2003;22: 
403-7.

28. Anderson MW, Kaplan PA, Dussault RG. Adductor insertion avulsion syndrome (thigh splints): spectrum of MR imaging features. Am J Roentgenol 2001;177:673-5.

29. Tshering-Vogel D, Waldherr C, Schindera ST, Steinbach LS, Stauffer E, Anderson SE. Adductor insertion avulsion syndrome, "thigh splints": relevance of radiological follow-up. Skeletal Radiol 2005;34:355-8.

30. Gottsegen CJ, Eyer BA, White EA, Learch TJ, Forrester D. Avulsion fractures of the knee: imaging findings and clinical significance. Radiographics 2008;28:1755-70.

31. Hayes CW, Brigido MK, Jamadar DA, Propeck T. Mechanism-based pattern approach to classification of complex injuries of the knee depicted at MR imaging. Radiographics 2000; 20 Spec No:S121-34.

32. Weber WN, Neumann CH, Barakos JA, Petersen SA, Steinbach LS, Genant HK. Lateral tibial rim (Segond) fractures: MR imaging characteristics. Radiology 1991;180:731-4.

33. Haims AH, Medvecky MJ, Pavlovich RJr, Katz LD. MR imaging of the anatomy of and injuries to the lateral and posterolateral aspects of the knee. Am J Roentgenol 2003;180:647-53.

34. Campos JC, Chung CB, Lektrakul N, Pedowitz R, Trudell D, Yu $\mathrm{J}$, et al. Pathogenesis of the Segond fracture: anatomic and MR imaging evidence of an iliotibial tract or anterior oblique band avulsion. Radiology 2001;219:381-6.

35. Terry GC, Hughston JC, Norwood LA. The anatomy of the iliopatellar band and iliotibial tract. Am J Sports Med 1986;14: $39-45$.

36. Porrino J Jr, Maloney E, Richardson M, Mulcahy H, Ha A, Chew FS. The anterolateral ligament of the knee: MRI appearance, association with the Segond fracture, and historical perspective. Am J Roentgenol 2015;204:367-73.

37. De Maeseneer M, Boulet C, Willekens I, Lenchik L, De Mey J, Cattrysse E, et al. Segond fracture: involvement of the iliotibial band, anterolateral ligament, and anterior arm of the biceps femoris in knee trauma. Skeletal Radiol 2015;44:413-21.

38. Stallenberg B, Gevenois PA, Sintzoff SA Jr, Matos C, Andrianne Y, Struyven J. Fracture of the posterior aspect of the lateral tibial plateau: radiographic sign of anterior cruciate ligament tear. Radiology 1993; 187:821-5.

39. Ringenberg J, Sealy D, Tiller R. Isolated Segond fracture in a pediatric patient. Phys Sportsmed 2015;43:188-91.

40. Hall FM, Hochman MG. Medial Segond-type fracture: cortical avulsion off the medial tibial plateau associated with tears of the posterior cruciate ligament and medial meniscus. Skeletal Radiol 1997;26:553-5.

41. Remer EM, Fitzgerald SW, Friedman H, Rogers LF, Hendrix
RW, Schafer MF. Anterior cruciate ligament injury: MR imaging diagnosis and patterns of injury. Radiographics 1992;12: 901-15.

42. Capps GW, Hayes CW. Easily missed injuries around the knee. Radiographics 1994;14:1191-210.

43. Delzell PB, Schils JP, Recht MP. Subtle fractures about the knee: innocuous-appearing yet indicative of significant internal derangement. Am J Roentgenol 1996;167:699-703.

44. Kendall NS, Hsu SY, Chan KM. Fracture of the tibial spine in adults and children. A review of 31 cases. J Bone Joint Surg Br 1992;74:848-52.

45. Recondo JA, Salvador E, Villanúa JA, Barrera MC, Gervás C, Alústiza JM. Lateral stabilizing structures of the knee: functional anatomy and injuries assessed with MR imaging. Radiographics 2000;20 Spec No:S91-102.

46. Huang GS, Yu JS, Munshi M, Chan WP, Lee CH, Chen CY, et al. Avulsion fracture of the head of the fibula (the "arcuate" sign): MRimaging findings predictive of injuries to the posterolateral ligaments and posterior cruciate ligament. Am J Roentgenol 2003;180:381-7.

47. Lee J, Papakonstantinou O, Brookenthal KR, Trudell D, Resnick DL. Arcuate sign of posterolateral knee injuries: anatomic, radiographic, and MR imaging data related to patterns of injury. Skeletal Radiol 2003;32:619-27.

48. Flato R, Passanante GJ, Skalski MR, Patel DB, White EA, Matcuk GR Jr. The iliotibial tract: imaging, anatomy, injuries, and other pathology. Skeletal Radiol 2017;46:605-22.

49. Bates DG, Hresko MT, Jaramillo D. Patellar sleeve fracture: demonstration with MR imaging. Radiology 1994;193:825-7.

50. Hunt DM, Somashekar N. A review of sleeve fractures of the patella in children. Knee 2005;12:3-7.

51. Dupuis CS, Westra SJ, Makris J, Wallace EC. Injuries and conditions of the extensor mechanism of the pediatric knee. Radiographics 2009;29:877-86.

52. Jalgaonkar AA, Dachepalli S, Al-Wattar Z, Rao S, Kochhar T. Atypical tibial tuberosity fracture in an adolescent. Orthopedics 2011;34:215.

53. Rosenberg ZS, Kawelblum M, Cheung YY, Beltran J, Lehman $\mathrm{WB}$, Grant AD. Osgood-Schlatter lesion: fracture or tendinitis? Scintigraphic, CT, and MR imaging features. Radiology 1992; 185:853-8

54. Yablon CM, Pai D, Dong Q Jacobson JA. Magnetic resonance imaging of the extensor mechanism. Magn Reson Imaging Clin NAm 2014;22:601-20.

55. Hirano A, Fukubayashi T, Ishii T, Ochiai N. Magnetic resonance imaging of Osgood-Schlatter disease: the course of the disease. Skeletal Radiol 2002;31:334-42. 
56. Ekrol I, Court-Brown CM. Fractures of the base of the 5th metatarsal. Foot 2004;14:96-8.

57. Gu YD, Ren XJ, Li JS, Lake MJ, Zhang QY, Zeng YJ. Computer simulation of stress distribution in the metatarsals at different inversion landing angles using the finite element method. Int Orthop 2010;34:669-76.

58. Theodorou DJ, Theodorou SJ, Kakitsubata Y, Botte MJ, Resnick D. Fractures of proximal portion of fifth metatarsal bone: anatomic and imaging evidence of a pathogenesis of avulsion of the plantar aponeurosis and the short peroneal muscle tendon. Radiology 2003;226:857-65.

59. Polzer H, Polzer S, Mutschler W, Prall WC. Acute fractures to the proximal fifth metatarsal bone: development of classification and treatment recommendations based on the current evidence. Injury 2012;43:1626-32.

60. Chuckpaiwong B, Queen RM, Easley ME, Nunley JA. Distinguishing Jones and proximal diaphyseal fractures of the fifth metatarsal. Clin Orthop Relat Res 2008;466:1966-70.

61. Kathol MH, el-Khoury GY, Moore TE, Marsh JL. Calcaneal insufficiency avulsion fractures in patients with diabetes mellitus. Radiology 1991;180:725-9.

62. Lee SM, Huh SW, Chung JW, Kim DW, Kim YJ, Rhee SK. Avulsion fracture of the calcaneal tuberosity: classification and its characteristics. Clin Orthop Surg 2012;4:134-8.

63. Yu SM, Yu JS. Calcaneal avulsion fractures: an often forgotten diagnosis. Am J Roentgenol 2015;205:1061-7.

64. Frame TS. Rockwood \& Green's fractures in adults. 4th ed. Philadelphia: Lippincott Williams \& Wilkins; 2006. p. 2023.

65. Davis WH, Sobel M, Deland J, Bohne WH, Patel MB. The superior peroneal retinaculum: an anatomic study. Foot Ankle Int 1994; 15:271-5.

66. Rosenberg ZS, Bencardino J, Astion D, Schweitzer ME, Rokito A, Sheskier S. MRI features of chronic injuries of the superior peroneal retinaculum. Am J Roentgenol 2003;181:1551-7.

67. Bahrs C, Lingenfelter E, Fischer F, Walters EM, Schnabel M. Mechanism of injury and morphology of the greater tuberosity fracture. J Shoulder Elbow Surg 2006; 15:140-7.

68. Green A, Izzi J Jr. Isolated fractures of the greater tuberosity of the proximal humerus. J Shoulder Elbow Surg 2003;12:641-9.

69. Pace A, Ribbans W, Kim JH. Isolated lesser tuberosity fracture of the humerus. Orthopedics 2008;31:94.

70. Earwaker J. Isolated avulsion fracture of the lesser tuberosity of the humerus. Skeletal Radiol 1990;19:121-5.
71. van Laarhoven HA, te Slaa RL, van Laarhoven EW. Isolated avulsion fracture of the lesser tuberosity of the humerus. J Trauma 1995;39:997-9.

72. Levine B, Pereira D, Rosen J. Avulsion fractures of the lesser tuberosity of the humerus in adolescents: review of the literature and case report. J Orthop Trauma 2005;19:349-52.

73. Wenzke DR. MR imaging of the elbow in the injured athlete. Radiol Clin North Am 2013;51:195-213.

74. Iyer RS, Thapa MM, Khanna PC, Chew FS. Pediatric bone imaging: imaging elbow trauma in children: a review of acute and chronic injuries. Am J Roentgenol 2012;198:1053-68.

75. Crowther M. Elbow pain in pediatrics. Curr Rev Musculoskelet Med 2009;2:83-7.

76. Rajasekhar C, Kakarlapudi TK, Bhamra MS. Avulsion of the triceps tendon. Emerg Med J 2002;19:271-2.

77. Newman SD, Mauffrey C, Krikler S. Olecranon fractures. Injury 2009;40:575-81.

78. Delgado J, Jaramillo D, Chauvin NA. Imaging the injured pediatric athlete: upper extremity. Radiographics 2016;36:1672-87.

79. Woods GW, Tullos HS. Elbow instability and medial epicondyle fractures. Am J Sports Med 1977;5:23-30.

80. Kobayashi Y, Oka Y, Ikeda M, Munesada S. Avulsion fracture of the medial and lateral epicondyles of the humerus. J Shoulder Elbow Surg 2000;9:59-64.

81. Dodds SD, Flanagin BA, Bohl DD, DeLuca PA, Smith BG. Incarcerated medial epicondyle fracture following pediatric elbow dislocation: 11 cases. J Hand Surg Am 2014;39:1739-45.

82. Kang R, Stern PJ. Fracture dislocations of the proximal interphalangeal joint. J Am Soc Surg Hand 2002;2:47-59.

83. Freiberg A, Pollard BA, Macdonald MR, Duncan MJ. Management of proximal interphalangeal joint injuries. J Trauma 1999; 46:523-8.

84. Ritting AW, Baldwin PC, Rodner CM. Ulnar collateral ligament injury of the thumb metacarpophalangeal joint. Clin J Sport Med 2010;20:106-12.

85. Simpson D, McQueen MM, Kumar P. Mallet deformity in sport. J Hand Surg Br 2001;26:32-3.

86. Aronowitz ER, Leddy JP. Closed tendon injuries of the hand and wrist in athletes. Clin Sports Med 1998;17:449-67.

87. Blair WF, Steyers CM. Extensor tendon injuries. Orthop Clin North Am 1992;23:141-8.

88. Cheung JP, Fung B, Ip WY. Review on mallet finger treatment. Hand Surg 2012;17:439-47. 